\title{
醏
}

\section{ESTADÍSTICAS DE LAS EXPORTACIONES ESPAÑOLAS DE MATERIAL DE DEFENSA, DE OTRO MATERIAL Y DE PRODUCTOS Y TECNOLOGÍAS DE DOBLE USO, AÑO 2014}

Las estadísticas que se publican en este número del Boletín Económico de ICE son enviadas a las Comisiones de Asuntos Exteriores y de Defensa del Congreso de los Diputados. De esta manera, se da cumplimiento a lo dispuesto en el artículo 16 de la Ley 53/2007, de 28 de diciembre, sobre el control del comercio exterior de material de defensa y de doble uso, al mismo tiempo que se ofrece una detallada información tanto de las operaciones de exportación de este tipo de productos como de las acciones acometidas en los foros internacionales de control y no proliferación en el año 2014.

Palabras clave: armas de caza y deportivas, productos y tecnologías de doble uso, exportaciones autorizadas y realizadas, foros internacionales de control y no proliferación, cláusula catch-all, embargos, denegaciones, Tratado Internacional sobre el Comercio de Armas, proliferación, armas de destrucción masiva.

Clasificación JEL: F10, H56.

\section{Introducción}

Este informe incorpora las exportaciones autorizadas y realizadas de material de defensa, de otro material y de productos y tecnologías de doble uso del año 2014 de acuerdo con lo dispuesto en el artículo 16 de la Ley 53/2007, de 28 de diciembre, sobre el control del comercio exterior de material de defensa y de doble uso.

Antes de entrar en el análisis de los datos concretos de exportación, es preciso explicar la metodología que se ha seguido en la elaboración de las estadísticas a las que se refiere el informe.

* Ministerio de Economía y Competitividad. Este artículo ha sido elaborado por Ramón Muro Martínez, Subdirector General de Comercio Internacional de Material de Defensa y Doble Uso y José Luis Valenzuela Vadillo, Jefe de Servicio.

Versión de junio de 2015.
El órgano encargado de autorizar cada una de las operaciones de comercio exterior de material de defensa, de otro material y de productos y tecnologías de doble uso, previo informe de la Junta Interministerial Reguladora del Comercio Exterior de Material de Defensa y Doble Uso (JIMDDU), es la Secretaría de Estado de Comercio adscrita al Ministerio de Economía y Competitividad. La Secretaría de Estado tiene los datos de todas las licencias de exportación autorizadas, mientras que los datos correspondientes a las exportaciones efectivamente realizadas están disponibles en el Departamento de Aduanas e Impuestos Especiales de la Agencia Estatal de Administración Tributaria adscrita al Ministerio de Hacienda y Administraciones Públicas.

El presente informe incluye los datos de las operaciones realizadas, habiendo sido obtenida esta $\triangle$ 
información contrastando el Departamento de Aduanas e IIEE una a una las licencias de exportación concedidas, y comprobando cada uno de los envíos realizados. Por otra parte, la Secretaría de Estado de Comercio ha recabado directamente de las empresas información sobre las exportaciones efectuadas para así poder corregir cualquier divergencia en los datos. Esta facultad aparece contemplada en el artículo 9 del Real Decreto 2061/2008, de 12 de diciembre, por el que se aprueba el Reglamento de control del comercio exterior de material de defensa, de otro material y de productos y tecnologías de doble uso, debiendo remitir semestralmente las empresas información sobre los despachos realizados.

Hay que precisar que en estas estadísticas no se han incluido las exportaciones temporales (envíos para reparaciones, homologaciones, pruebas, ferias, devoluciones a origen por material defectuoso) sin valor comercial.

\section{Legislación}

La Ley Orgánica 3/1992, de 30 de abril de 1992, introdujo por primera vez en la normativa nacional los delitos e infracciones administrativas en materia de contrabando para el material de defensa y de doble uso. La Ley 3/1992 tipificaba el delito de contrabando en los mismos términos que la Ley Orgánica 12/1995, de 12 de diciembre de 1995, de Represión del Contrabando, considerando como tal la exportación de material de defensa o de doble uso sin autorización o habiéndola obtenido mediante declaración falsa o incompleta.

La Ley Orgánica 12/1995 fue modificada en 2011 por medio de la Ley Orgánica 6/2011, de 30 de junio de 2011.

En lo que respecta a la legislación específica de control del comercio exterior de material de defensa y de doble uso, el 29 de enero de 2008 entró en vigor la Ley 53/2007, estando la legislación española en esta materia constituida por primera vez por una norma de este rango. Dicha Ley fue desarrollada a través del Real Decreto 2061/2008, de 12 de diciembre, por el que se aprobó el Reglamento de control del comercio exterior de material de defensa, de otro material y de productos y tecnologías de doble uso.

En el año 2011 fue necesario a su vez llevar a cabo una modificación del Real Decreto 2061/2008, de 12 de diciembre. La modificación se plasmó en el Real Decreto 844/2011, de 17 de junio de 2011, entrando en vigor el 2 de enero de 2012.

La última modificación en la legislación española en este campo tuvo lugar el 27 de agosto de 2014 con la entrada en vigor del Real Decreto 679/2014, de 1 de agosto, que sustituye al Real Decreto 2061/2008, modificado por el Real Decreto 844/2011. El Real Decreto 679/214 tiene como objeto introducir los cambios necesarios en la regulación de estas transferencias, completando y desarrollando lo establecido por la normativa comunitaria y la firma y ratificación por España del Tratado sobre el Comercio de Armas.

Las principales modificaciones se pueden resumir como sigue:

1. Se realiza la adaptación de la legislación española al Reglamento (UE) $n^{\circ}$ 258/2012, del Parlamento Europeo y del Consejo, de 14 de marzo de 2012, por el que se establecen autorizaciones de exportación y medidas de importación y tránsito para las armas de fuego, sus piezas y componentes y municiones, procedimientos simplificados para exportaciones temporales de estas armas, exigencia de autorización expresa de las autoridades de los países de tránsito (con excepciones) y la obligación de indicar el marcaje de las armas de fuego en la autorización de exportación. Las armas de fuego de uso civil, sus piezas y componentes y municiones se incluyen en el Anexo II.1 del Reglamento.

2. Se introduce una mención especial al Tratado sobre el Comercio de Armas, aprobado el 2 de abril de 2013 por la Asamblea General de la Organización de Naciones Unidas, firmado por España el 3 de junio de 2013 y ratificado el 2 de abril $\triangle$ 
de 2014, para aplicar los artículos 6 y 7 del Tratado referidos a «Prohibiciones» y a «Exportación y evaluación de las exportaciones». Se incorpora una referencia expresa a «la violación grave del derecho internacional de los derechos humanos o del derecho internacional humanitario" en el artículo 7.1.a.

3. Se incorporan a la legislación española las nuevas autorizaciones generales de exportación de la Unión Europea para la exportación de determinados productos y tecnologías de doble uso a países específicos.

4. Se incluye un nuevo apartado en el que se detalla el régimen de las introducciones de las transferencias intracomunitarias de mercancías procedentes de cualquier Estado miembro de la Unión Europea de material de defensa (artículo 2.1).

5. Se introduce una cláusula de salvaguardia en el caso de destinatarios certificados de conformidad con los criterios establecidos en el artículo 9 de la Directiva 2009/43/CE, que no respeten las condiciones vinculadas a una Licencia General de Transferencia, o si se viesen afectados el orden público, la seguridad pública o los intereses esenciales en materia de seguridad (artículo 7.3).

6. Se realiza la transposición de las Directivas 2010/80/UE de la Comisión de 22 de noviembre de 2010, 2012/10/UE de la Comisión de 22 de marzo de 2012, y 2012/47/UE de la Comisión de 14 de diciembre de 2012, y Directiva 2014/18/UE de la Comisión, de 29 de enero de 2014, y se incorporan las actualizaciones de la Lista Común Militar de la Unión Europea en lo referente a la actualización de la lista de productos relacionados con la defensa adoptada por el Consejo el 17 de marzo de 2014.

7. Se someten a autorización determinadas operaciones de explosivos y de equipos relacionados incluidos en las listas de equipos que pueden utilizarse con fines de represión interna, como consecuencia de la imposición por parte de la Unión Europea de medidas restrictivas a determinados destinos. Las autorizaciones se referirán exclusivamente a explosivos y equipos relacionados para uso civil en los sectores de la minería e infraestructuras.

8. Se unifican todas las competencias para resolver los procedimientos en el titular de la Secretaría de Estado de Comercio del Ministerio de Economía y Competitividad. La Subdirección General de Comercio Internacional de Material de Defensa y Doble Uso tramitará las solicitudes referidas en el Reglamento (artículos 5 y 8).

9. Se modifica la composición de la Junta Interministerial Reguladora del Comercio Exterior de Material de Defensa y de Doble Uso (JIMDDU), para actualizarla al Real Decreto 1/2012, de 5 de enero, por el que se modifica el Real Decreto 1823/2011, de 21 de diciembre, en el que se reestructuran los departamentos ministeriales (artículo 17).

10. Se amplía de cuatro a diez años el período en el que los titulares de las correspondientes autorizaciones deberán conservar los documentos relacionados con las respectivas operaciones, a contar desde la fecha de extinción del plazo de validez de la autorización para equipararlo al plazo indicado en el texto del Tratado de Comercio de Armas (artículo 9).

11. Se modifica el régimen de las rectificaciones de las autorizaciones, podrán ser referidas únicamente al plazo de validez y al valor monetario, no siendo necesarias en el caso de cambio de aduana, al haberse incluido una nueva casilla en la licencia con espacio para declarar cinco aduanas. Además, se restringe el número de rectificaciones a dos por cada licencia original y se fija que el plazo de validez de la rectificación será el mismo que el de la licencia original contado desde la autorización de la licencia original (artículos 18.6.h y 31 apartados 4 y 5).

12. Se modifica la exigencia de documentos de control, especialmente para armas de caza de uso civil (artículo 30).

13. Se actualizan los anexos correspondientes a los modelos de licencias, la solicitud de inscripción en el Registro Especial de Operadores $\triangleright$ 
de Comercio Exterior de Material de Defensa y de Doble Uso (REOCE) y documentos de control. Se divide el Anexo II en Anexo II.1 (arma deportiva y de caza) y II.2 (antidisturbios). Se actualizan los anexos de las listas de productos sometidos a control de acuerdo con los cambios habidos en las listas de los foros internacionales de control.

14. Se amplía el plazo de seis a doce meses para volver a transferir la mercancía en el caso de transferencias temporales, de acuerdo con el artículo 140 del Reglamento (CEE) n² 2913/92 del Consejo, de 12 de octubre de 1992, por el que se aprueba el Código Aduanero Comunitario (artículo 22.5).

15. Se simplifican los trámites de los regímenes aduaneros para evitar dobles autorizaciones en un mismo procedimiento.

En el apartado específico de la tramitación de las operaciones es importante destacar que el análisis de las solicitudes de transferencia se efectúa de acuerdo con la citada legislación (Ley 53/2007 y Real Decreto 679/2014), analizando caso por caso y recabando el informe preceptivo y vinculante de la JIMDDU. Dicho análisis tiene como fundamento primordial el impedir la exportación de material de defensa a destinos en los que no se cumplan los ocho criterios de la Posición Común 2008/944/PESC, de 8 de diciembre de 2008, por la que se definen las normas comunes que rigen el control de las exportaciones de tecnología y equipos militares, así como la proliferación de armas de destrucción masiva.

Concretamente, en las operaciones de exportación de material de defensa se tienen en cuenta los ocho criterios de la Posición Común 2008/944/ PESC y, además en las de armas pequeñas y ligeras, los criterios del Documento OSCE sobre armas pequeñas y armas ligeras de 24 de octubre de 2000.

Son también de aplicación la Resolución 55/255 de la Asamblea General de Naciones Unidas, de 8 de junio de 2001, por la que se aprueba el Protocolo contra la fabricación y el tráfico ilícitos de armas de fuego, sus piezas y componentes y municiones, que complementa la Convención de las Naciones Unidas contra la Delincuencia Organizada Transnacional; el Programa de Acción de Naciones Unidas para prevenir, combatir y eliminar el tráfico ilícito de armas pequeñas y ligeras en todos sus aspectos, así como el Reglamento (UE) $n^{\circ}$ 258/2012 del Parlamento Europeo y del Consejo, de 14 de marzo de 2012, por el que se aplica el artículo 10 de dicho Protocolo. En este ámbito, es preciso mencionar la Posición Común del Consejo, 2003/468/PESC, de 23 de junio de 2003, sobre el control del corretaje de armas, y el control de la asistencia técnica en relación con determinados usos finales militares a que se refiere la Acción Común del Consejo de 22 de junio de 2000.

De manera análoga, cabe mencionar lo dispuesto en este ámbito en el Reglamento de Armas, aprobado por el Real Decreto 137/1993, de 29 de enero de 1993, y modificado por el Real Decreto 976/2011, de 8 de julio de 2011, en el Reglamento de Explosivos, aprobado por el Real Decreto 230/1998, de 16 de febrero de 1998, y modificado por el Real Decreto 248/2010, de 5 de marzo de 2010, así como en el Real Decreto 563/2010, de 7 de mayo, por el que se aprueba el Reglamento de artículos pirotécnicos y cartuchería, modificado por el Real Decreto 1335/2012, de 21 de septiembre de 2012.

Asimismo, y en la vertiente del doble uso, las autoridades españolas de control aplican el Reglamento (CE) no 428/2009 del Consejo, de 5 de mayo de 2009, por el que se establece un régimen comunitario de control de las exportaciones, la transferencia, el corretaje y el tránsito de productos de doble uso, modificado por los Reglamentos (UE) n ${ }^{\circ} 1232 / 2011$ del Parlamento Europeo y del Consejo, de 16 de noviembre de 2011, y n ${ }^{\circ}$ 599/2014 del Parlamento Europeo y del Consejo de 16 de abril de 2014.

Es importante destacar también la Resolución 1540 (2004), de 28 de abril, de las Naciones Unidas dirigida a impedir la proliferación de armas de destrucción masiva y, en particular, impedir y contrarrestar la adquisición y el uso por agentes no estatales de estas armas. 
Otras normas internacionales son las contenidas en la Convención sobre prohibiciones o restricciones del empleo de ciertas armas convencionales que puedan considerarse excesivamente nocivas o de efectos indiscriminados de 1980 (en concreto, en el Protocolo II sobre prohibiciones o restricciones del empleo de minas, armas trampa y otros artefactos), la Convención sobre la prohibición del empleo, almacenamiento, producción y transferencia de minas antipersonal y sobre su destrucción (Convención sobre minas antipersonal) de 3 de diciembre de 1997, la Convención sobre Municiones en Racimo de 3 de diciembre de 2008, la Convención sobre la prohibición del desarrollo, la producción, el almacenamiento y el empleo de armas químicas y sobre su destrucción de 13 enero de 1993, y la Convención sobre la prohibición de desarrollo, producción y almacenamiento de las armas bacteriológicas (biológicas) y toxínicas y sobre su destrucción, de 10 de abril de 1972.

En el año 2013 se procedió a la tramitación de la modificación de la Ley 33/1998, de 5 de octubre de 1998, de prohibición total de minas antipersonal y armas de efecto similar, con el fin de poder incluir las prohibiciones referidas a las municiones de racimo. La modificación está pendiente de aprobación parlamentaria.

El sistema español de control asume las obligaciones contraídas en el seno de los principales foros internacionales de control y no proliferación, como son el Arreglo de Wassenaar, el Comité Zangger, el Régimen de Control de la Tecnología de Misiles, el Grupo de Suministradores Nucleares y el Grupo Australia.

\section{3. Órganos de control}

\subsection{Junta Interministerial Reguladora del Comercio Exterior de Material de Defensa y Doble Uso}

La Junta Interministerial Reguladora del Comercio Exterior de Material de Defensa y de Doble
Uso (JIMDDU) se constituyó por primera vez en 1988 como órgano administrativo interministerial, estando adscrita funcionalmente al Ministerio de Economía y Competitividad. La JIMDDU se reúne una vez al mes, salvo en el mes de agosto, existiendo un Grupo de Trabajo preparatorio de las operaciones e informes.

Su composición está regulada en el artículo 13 de la Ley 53/2007 y el artículo 17 del Real Decreto 679/2014. Están representadas aquellas unidades de la Administración directamente implicadas en el control del comercio exterior de material de defensa, de otro material y de productos y tecnologías de doble uso (Ministerios de la Presidencia, Asuntos Exteriores y de Cooperación, Defensa, Economía y Competitividad, Hacienda y Administraciones Públicas, Interior e Industria, Energía y Turismo).

La función más relevante de la JIMDDU consiste en informar, con carácter preceptivo y vinculante, las autorizaciones administrativas y acuerdos previos de los citados materiales y, preceptivamente, las modificaciones en la normativa reguladora de este comercio.

\subsection{Secretaría de Estado de Comercio}

La autorización de las operaciones de exportación e importación de material de defensa, de otro material y de productos y tecnologías de doble uso, previo informe de la JIMDDU, corresponde a la Secretaría de Estado de Comercio. El proceso de tramitación de las licencias es realizado por la Subdirección General de Comercio Internacional de Material de Defensa y Doble Uso, que actúa a su vez de Secretaría de la JIMDDU.

\section{Material de defensa}

\subsection{Legislación aplicable}

La legislación aplicable en el período descrito en estas estadísticas estaba constituida por la Ley $\triangleright$ 
Orgánica 12/1995, de 10 de diciembre de 1995, de Represión del Contrabando, modificada por la Ley Orgánica 6/2011, de 30 de junio, la Ley 53/2007, de 28 de diciembre de 2007, de control del comercio exterior de material de defensa y de doble uso, el Real Decreto 2061/2008, de 12 de diciembre, modificado por el Real Decreto 844/2011, hasta el 26 de agosto y, a partir del 27 de agosto, el Real Decreto 679/2014, de 1 de agosto por el que se aprueba el Reglamento de control del comercio exterior de material de defensa, de otro material y de productos y tecnologías de doble uso.

El material de defensa sometido a control en la legislación española se basa en la Lista Militar del Arreglo de Wassenaar y en la Lista Común Militar de la Posición Común 2008/944/PESC, de 8 de diciembre, por la que se definen las normas comunes que rigen el control de las exportaciones de tecnología y equipos militares, adoptada por el Consejo el 11 de marzo de 2013, además de incorporar las categorías I y II del Régimen de Control de la Tecnología de Misiles.

\subsection{Exportaciones realizadas}

En el año 2014, se produjo un descenso del 18,0 por 100 en las exportaciones de material de defensa con respecto a 2013. El valor de lo exportado totalizó $3.203,2$ millones de euros.

\section{CUADRO 1}

EXPORTACIONES DE MATERIAL DE DEFENSA (2008-2014)

\begin{tabular}{|c|c|}
\hline Año & Valor (millones de euros) \\
\hline 2008 & 934,4 \\
2009 & $1.346,5$ \\
2010 & $1.128,3$ \\
2011 & $2.431,2$ \\
2012 & $1.953,5$ \\
2013 & $3.907,9$ \\
2014 & $3.203,2$ \\
\hline
\end{tabular}

Fuente: Subdirección General de Comercio Internacional de Material de Defensa y Doble Uso. Ministerio de Economía y Competitividad.

Los principales mercados de la exportación española se indican en el Cuadro 2.

\begin{tabular}{|c|c|c|}
\hline \multicolumn{3}{|c|}{$\begin{array}{c}\text { CUADRO } 2 \\
\text { EXPORTACIÓN ESPAÑOLA DE MATERIAL DE DEFENSA POR } \\
\text { PAÍSES Y ZONAS DE DESTINO }\end{array}$} \\
\hline Países MD & $\begin{array}{l}\text { Valor } \\
\text { (millones } \\
\text { de euros) }\end{array}$ & Porcentaje \\
\hline Países UE OTAN & $1.817,8$ & 56,7 \\
\hline 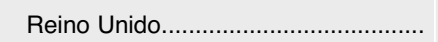 & 862,7 & 26,9 \\
\hline Francia ............................ & 520,7 & 16,3 \\
\hline Alemania ....................... & 272,4 & 8,5 \\
\hline Italia .... & 96,1 & 3,0 \\
\hline 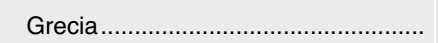 & 47,4 & 1,5 \\
\hline Resto & 18,5 & 0,5 \\
\hline Países UE no OTAN & 13,0 & 0,4 \\
\hline Suecia & 10,1 & 0,3 \\
\hline Austria & 1,6 & 0,1 \\
\hline 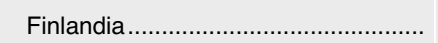 & 0,7 & 0,0 \\
\hline Irlanda ........................... & 0,6 & 0,0 \\
\hline Resto & 0,0 & 0,0 \\
\hline 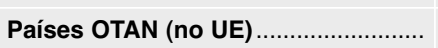 & 283,0 & 8,9 \\
\hline 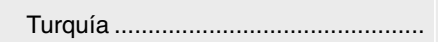 & 243,7 & 7,6 \\
\hline 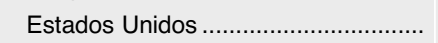 & 34,0 & 1,1 \\
\hline 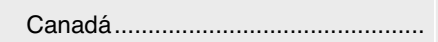 & 3,3 & 0,1 \\
\hline Noruega & 2,0 & 0,1 \\
\hline OTAN + UE & $2.113,8$ & 66,0 \\
\hline 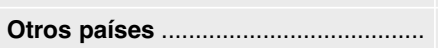 & 651,6 & 20,3 \\
\hline 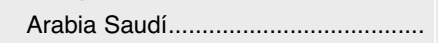 & 292,9 & 9,1 \\
\hline Australia & 139,7 & 4,4 \\
\hline Indonesia & 112,0 & 3,5 \\
\hline Egipto & 107,0 & 3,3 \\
\hline 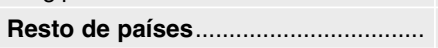 & 437,8 & 13,7 \\
\hline TOTAL & $3.203,2$ & 100,0 \\
\hline \multicolumn{3}{|c|}{$\begin{array}{l}\text { Fuente: Subdirección General de Comercio Internacional de } \\
\text { Material de Defensa y Doble Uso. Ministerio de Economía y } \\
\text { Competitividad. }\end{array}$} \\
\hline
\end{tabular}

Las expediciones a los países de la Unión Europea representaron un 57,1 por 100 del total. En valor, estas ventas supusieron $1.830,8$ millones de euros frente a 1.414,2 millones de euros en 2013. Dichas expediciones volvieron a recuperarse en valor y en porcentaje respecto a años anteriores.

Las expediciones estuvieron distribuidas principalmente entre Reino Unido, Francia, Alemania, Italia y Grecia.

Las expediciones al Reino Unido, por un valor de 862,7 millones de euros y un 26,9 por 100 , correspondieron a tres aviones de reabastecimiento en vuelo (573,9 millones de euros) y un avión de transporte (121,8 millones de euros), partes y piezas para el caza de combate EF-2000 y del avión de transporte militar A400M. Otras categorías en $\square$ 
las expediciones al Reino Unido fueron las de combustibles militares, componentes de submarinos, equipos electrónicos, datos técnicos e instrucciones relativos a un programa de construcción de vehículos blindados, partes y piezas de helicóptero (programa Tigre), reparación de partes y piezas de motores de aeronaves de la Armada Española, componentes de helicópteros Sikorsky, componentes de aeronaves y submarinos, partes y piezas de misiles (programa Meteor), partes y piezas de vehículos blindados, detectores de infrarrojos, granadas de mortero, diversa munición y rifles de caza con accesorios.

Las expediciones a Francia, con 520,7 millones de euros y un 16,3 por 100 , estuvieron compuestas por cuatro aviones de transporte ( 477,5 millones de euros) partes y piezas para el avión de transporte militar A400M, partes y piezas de helicóptero (programa Tigre y $\mathrm{NH}-90$ ), partes y piezas de misiles (Meteor, Milan y Mistral), partes y piezas de radares (programa MIDS), componentes electrónicos y equipos de comunicaciones, combustibles militares, pólvora y diversa munición, pistolas y rifles de caza con sus piezas.

En los envíos a Alemania, con 272,4 millones de euros y un 8,5 por 100 , cabe mencionar, además de partes y piezas para el caza de combate EF-2000 y del avión de transporte militar A400M, partes y piezas de helicópteros (programa Tigre), de carros de combate y de misiles (Iris-T y Meteor), partes y piezas de radares (programa MIDS), componentes de carros de combate (Leopard y Pizarro), sistemas de guerra electrónica, una estación de comunicación vía satélite, pólvora, diversa munición, pistolas y rifles de caza con sus piezas.

Las expediciones a Italia, con 96,1 millones de euros y un 3,0 por 100 , estuvieron representadas por partes y piezas del caza de combate EF-2000, del avión de transporte militar A400M y del helicóptero NH-90, partes y piezas de radares (programa MIDS), piezas para buques, repuestos para reparación de vehículos anfibios, combustibles militares, placas balísticas, detonadores eléctricos, devolución a origen de material para montaje de obús, diverso material para destrucción, devolución a origen de cañón, cabezas de guerra de torpedos, componentes de torre para vehículos blindados, pólvora y diversa munición, morteros, pistolas y rifles de caza con sus piezas.

Las expediciones a Grecia, por valor de 47,4 millones de euros y un 1,5 por 100, consistieron en combustibles militares, tecnología para la fabricación de helicópteros y una pistola.

Los países OTAN absorbieron un 65,6 por 100 de las expediciones/exportaciones, con 2.100,8 millones de euros.

Las ventas restantes $(1.089,4$ millones de euros y un 34,0 por 100), una vez descontadas las expediciones/exportaciones a países de la UE y países OTAN, se repartieron entre 49 países.

Por categorías de productos, destacó por encima de todas la de «aeronaves», con 2.598,9 millones de euros y un 81,1 por 100 del total.

El valor de las exportaciones derivadas de programas de cooperación ascendió a 1.864,2 millones de euros, representando un 58,2 por 100 del total.

Las exportaciones realizadas $(3.203,2$ millones de euros) supusieron un 87,4 por 100 de lo autorizado (3.666,4 millones de euros).

\subsection{Denegaciones, suspensiones y revocaciones}

En 2014 hubo una denegación de exportación de material de defensa en aplicación de la Posición Común 2008/944/PESC, de 8 de diciembre, por la que se definen las normas comunes que rigen el control de las exportaciones de tecnología y equipos militares:

- Un acuerdo previo de exportación a Sudán del Sur de cuatro aviones de transporte. Esta operación fue denegada en aplicación de los criterios 2 (respeto de derechos humanos), 3 (situación interna), 7 (riesgo de desvío) y 8 (adecuación económica y técnica de la exportación) de la mencionada Posición Común. 
Asimismo, la Unión Europea adoptó el 31 de julio y el 8 de septiembre una tercera fase de sanciones a Rusia que se tradujo en un embargo a la exportación e importación de armas y material relacionado. No obstante, se estableció una cláusula de salvaguardia relativa a los contratos 0 acuerdos celebrados antes de la fecha de entrada en vigor de las sanciones ( 1 de agosto y 12 de septiembre de 2014).

En el año 2014 se colaboró con un país aliado en una investigación referida a una empresa española en la posible realización de actividades en Irán que podrían haber contravenido las sanciones impuestas por las Naciones Unidas.

A la hora de informar las operaciones en el año 2014, la JIMDDU llevó a cabo un análisis caso por caso de las mismas, aplicando los siguientes parámetros:

a) Respeto de los embargos vigentes de las Naciones Unidas, la Unión Europea y la OSCE (Anexo VII).

b) Cumplimiento de los compromisos asumidos en los foros internacionales de control y no proliferación en los que España participa.

c) Aplicación de los ocho criterios de la Posición Común 2008/944/PESC, de 8 de diciembre, por la que se definen las normas comunes que rigen el control de las exportaciones de tecnología y equipos militares.

d) Aplicación de los criterios del Documento OSCE sobre armas pequeñas y armas ligeras de 24 de octubre de 2000.

e) Adopción de principios restrictivos en la aprobación de exportaciones a determinados países inmersos en una situación de conflicto interno o regional, impidiendo los envíos de armas o equipos que por sus características pudiesen utilizarse para atentar contra la vida y la integridad física de las personas o que pudiesen ser empleados en la represión interna o como material antidisturbios.

f) En lo referente a las operaciones de arma pequeña y ligera, la JIMDDU tomó la decisión durante el año 2001 de condicionar la autorización de las exportaciones de estas armas, en el caso de países con una especial sensibilidad o en los que existiese riesgo de desvío en el uso final, a que el destinatario/usuario final tuviese una naturaleza pública (fuerzas armadas y fuerzas y cuerpos de seguridad).

Durante el año 2014, se siguió exigiendo un documento de control en el que se especifique este extremo antes de autorizar la licencia.

g) Desde diciembre de 2001 están prohibidas las exportaciones desde España de determinados dispositivos restrictivos del movimiento de los seres humanos, tales como grilletes para pies y cadenas para cintura.

Esta prohibición se incorporó como disposición adicional duodécima en la Ley 24/2001 de Medidas Fiscales, Administrativas y del Orden Social, de 27 de diciembre.

h) Desde julio de 2008 está prohibido el comercio exterior de las municiones de racimo, como consecuencia del establecimiento de una moratoria unilateral sobre el empleo, el desarrollo, la producción, la adquisición y el comercio exterior de las municiones de racimo, por Acuerdo aprobado en el Consejo de Ministros de 11 de julio de 2008.

Con posterioridad a esta moratoria, España depositó el instrumento de ratificación de la Convención sobre Municiones de Racimo el 17 de junio de 2009. La Convención entró en vigor el 1 de agosto de 2010, una vez alcanzado el número mínimo de ratificaciones por 30 Estados.

\section{Otro material (equipos policiales, antidisturbios y arma deportiva y de caza)}

\subsection{Legislación aplicable}

Las armas de caza y deportivas con cañón de ánima lisa, y sus municiones, que por sus especificaciones técnicas no hacen posible un uso militar y que no son totalmente automáticas, no estuvieron sometidas a control hasta la entrada en $\triangleright$ 
vigor de la Ley 53/2007 (29 de enero de 2008). Esta norma amplió el control a todas las armas de caza y deportivas, sus componentes y municiones, de acuerdo con los compromisos establecidos en la Resolución 55/255, de 8 de junio de 2001, de la Asamblea General de Naciones Unidas, por la que se aprueba el Protocolo contra la fabricación y el tráfico ilícitos de armas de fuego, sus piezas y componentes y municiones, que complementa la Convención de las Naciones Unidas contra la delincuencia transnacional organizada.

El Reglamento 679/2014, de 1 de agosto, adaptó la legislación española en este campo al Reglamento (UE) n ${ }^{\circ}$ 258/2012 del Parlamento Europeo y del Consejo, de 14 de marzo de 2012, por el que se aplica el artículo 10 del citado Protocolo.

\subsection{Exportaciones realizadas}

Por lo que respecta a las operaciones realizadas de material policial y de seguridad, lo exportado ascendió a 9,9 millones de euros, teniendo como destinos Túnez (2,9 millones de euros, 28,9 por 100), Bolivia (2,8 millones de euros, 28,8 por 100 ), Perú (1,7 millones de euros, 17,0 por 100$)$, Venezuela (1,5 millones de euros, 14,9 por 100), Libia ( 0,7 millones de euros, 7,0 por 100$)$ y Togo $(0,3 \mathrm{mi}-$ llones de euros, 3,4 por 100). Las exportaciones realizadas a Venezuela fueron con cargo a licencias vigentes que habían sido autorizadas en 2013 y, en cualquier caso, antes de la suspensión el 21 de marzo de 2014 de todas las licencias de material antidisturbios. La suspensión sigue vigente.

Las exportaciones realizadas supusieron un 102,9 por 100 de lo autorizado en el mismo período (9,7 millones de euros).

En lo relativo a las operaciones de armas de caza y deportivas (escopetas de caza, cartuchos y sus piezas y recambios), las exportaciones realizadas ascendieron a 46,4 millones de euros. Lo realizado representó un 38,9 por 100 de lo autorizado (119,3 millones de euros) en el mismo período.
El destino principal fue Estados Unidos, con 18,9 millones de euros y un 40,8 por 100 . Las operaciones restantes estuvieron repartidas entre 57 destinos.

Un 80,6 por 100 de estas exportaciones estuvo constituido por cartuchos de caza, un 8,4 por 100 a vainas, un 6,0 por 100 a escopetas, un 3,9 por 100 a pólvora, un 0,7 por 100 a perdigones, un 0,3 por 100 a pistones y un 0,06 por 100 a partes y componentes de estas armas y municiones.

\subsection{Denegaciones, suspensiones $y$ revocaciones}

Hubo cinco denegaciones de exportaciones de otro material en 2014. Dichas denegaciones tuvieron el siguiente desglose:

- Una licencia de exportación a Guinea Bissau de cartuchos de caza, que fue informada desfavorablemente debido a la situación de inestabilidad interna y el riesgo de desvío existentes en el país de destino.

- Cuatro licencias de exportación a Egipto de botes de gas lacrimógeno con sus componentes, que fueron denegadas debido a la situación de inestabilidad interna y al riesgo de uso indebido del producto.

Además de las anteriores denegaciones, el Gobierno español decidió adoptar una serie de medidas urgentes como resultado de los acontecimientos sucedidos en Venezuela y Ucrania en los meses de febrero y marzo de 2014.

Así, la Secretaría de Estado de Comercio, previo informe de la JIMDDU, acordó suspender el 21 de marzo de 2014 las licencias de exportación de armas de fuego y de municiones de caza a Ucrania y de material antidisturbios y de caza a Venezuela que se encontraban vigentes. Hay que hacer notar que no había habido ninguna operación autorizada a Ucrania desde el año 2003 correspondiente a material de defensa o a equipos antidisturbios y policiales al margen de una licencia de exportación para rifles de caza, objeto de dicha suspensión. 
En el caso de Ucrania, España aplicó las conclusiones adoptadas por el Consejo de Asuntos Exteriores de la Unión Europea del 20 de febrero de 2014. Estas conclusiones incluían, entre otros aspectos, el acuerdo consistente en suspender las exportaciones a dicho país de equipos que pudieran ser utilizados en represión interna.

La suspensión a este país afectó a doce licencias de exportación consistentes en escopetas y rifles de caza, así como diversas cantidades de cartuchos de caza, perdigones, vainas con pistón, pistones de escopetas y pólvora para la fabricación de cartuchos.

Dicha suspensión fue objeto de revisión, levantándose el 4 de julio para las ocho licencias que estaban en vigor.

Por lo que respecta a Venezuela, España se adelantó a la mayoría de los países de la Unión Europea en la posible imposición de medidas cautelares. La suspensión se extendió a quince licencias de material antidisturbios y a una licencia de cartuchos de caza.

Se colaboró con las Naciones Unidas en un caso de posible violación del embargo a la exportación de armas a la República Centroafricana, con la entrada a través de la frontera de un país limítrofe de munición de caza fabricada por una empresa española.

\section{Productos y tecnologías de doble uso}

\subsection{Legislación aplicable}

Por lo que respecta a la regulación del comercio exterior de productos y tecnologías de doble uso, ésta viene recogida en el Reglamento (CE) $n^{\circ} 428 / 2009$, de 5 de mayo de 2009, por el que se establece un régimen comunitario de control de las exportaciones, la transferencia, el corretaje y el tránsito de productos de doble uso, modificado por los Reglamentos (UE) No 1232/2011 del Parlamento Europeo y del Consejo, de 16 de noviembre de 2011, N 599/2014 del Parlamento
Europeo y del Consejo de 16 de abril de 2014 y n $^{\circ}$ 1382/2014 de la Comisión de 22 de octubre de 2014.

El Reglamento comunitario establece un régimen por el cual deben ser controlados en la exportación los productos y tecnologías de doble uso incluidos en su Anexo I (lista de control de 10 categorías de productos y tecnologías de doble uso), así como otros no incluidos en esta lista según su artículo 4 (cláusula escoba o catch-all).

En su Anexo IV se incluye el subconjunto de productos y tecnologías de doble uso cuyas expediciones dentro de la Unión Europea deben ser sometidas a control por su especial sensibilidad.

Es preciso mencionar también la Acción Común 2000/401/PESC, de 22 de junio, para el control de la asistencia técnica con determinados usos militares. En ella se presta una especial atención al control de la asistencia técnica (incluida la transmisión oral de la misma) que pudiera fomentar o servir de base para el desarrollo de armas de destrucción masiva. La Acción Común introduce el sometimiento a control de la asistencia técnica prestada a países no comunitarios, permitiendo a los Estados miembros elegir entre un sistema de autorización o uno de prohibición.

Por otra parte, se insta a los Estados miembros a que consideren la posible imposición de controles cuando la asistencia técnica tenga un uso final militar convencional y vaya dirigida a países sometidos a embargos internacionales.

\subsection{Exportaciones realizadas}

Las exportaciones realizadas de doble uso en 2014 experimentaron un aumento del 11,1 por 100 respecto a 2013, con 168,5 millones de euros.

Los diez primeros destinos fueron los que se relacionan en el Cuadro 4.

El primer destino en importancia de las exportaciones españolas fue Estados Unidos con 30,8 millones de euros y un 18,3 por 100 .

Los envíos consistieron en electrodos de grafito para hornos eléctricos en acerías, sustancias $D$ 


\begin{tabular}{|l|c|}
\hline \multicolumn{2}{c}{ CUADRO 3} \\
EXPORTACIONES DE PRODUCTOS Y TECNOLOGIAS \\
DE DOBLE USO (2008-2014)
\end{tabular}

\begin{tabular}{|c|c|c|}
\hline \multicolumn{3}{|c|}{$\begin{array}{c}\text { CUADRO } 4 \\
\text { EXPORTACIONES DE PRODUCTOS Y TECNOLOGÍAS DE DOBLE } \\
\text { USO POR PAÍSES (2014) }\end{array}$} \\
\hline Países DU & $\begin{array}{l}\text { Valor } \\
\text { (millones } \\
\text { euros) }\end{array}$ & Porcentaje \\
\hline Países más relevantes ................................ & 142,5 & 84,6 \\
\hline Estados Unidos .............................. & 30,8 & 18,3 \\
\hline Irán & 26,4 & 15,7 \\
\hline RP China. & 23,3 & 13,8 \\
\hline Rusia & 14,4 & 8,5 \\
\hline Canadá & 10,1 & 5,9 \\
\hline Venezuela & 9,3 & 5,5 \\
\hline México & 7,8 & 4,7 \\
\hline 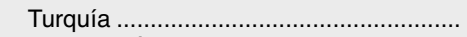 & 7,5 & 4,5 \\
\hline Emiratos Árabes Unidos & 6,9 & 4,1 \\
\hline Japón & 6,0 & 3,6 \\
\hline Resto de países & 26,0 & 15,4 \\
\hline TOTAL & 168,5 & 100,0 \\
\hline $\begin{array}{l}\text { Fuente: Subdirección General de Co } \\
\text { Material de Defensa y Doble Uso. Mi } \\
\text { Competitividad. }\end{array}$ & $\begin{array}{l}\text { rcio In } \\
\text { terio d }\end{array}$ & $\begin{array}{l}\text { cional de } \\
\text { gonomía y y }\end{array}$ \\
\hline
\end{tabular}

químicas con destino a los sectores químico e industrial, once máquinas-herramienta para el sector aeronáutico, un teléfono móvil, tarjetas y diverso material para el sector de telecomunicaciones, cámaras infrarrojas para el sector industrial y componentes para satélites.

El segundo mercado fue Irán, ascendiendo las exportaciones realizadas a 26,4 millones de euros y un 15,7 por 100 .

Las operaciones de exportación a Irán fueron analizadas caso por caso por la JIMDDU y la Secretaría de Estado de Comercio, teniendo en cuenta las sanciones de la ONU y la UE a este destino.

Las exportaciones a Irán de productos y tecnologías de doble uso fueron el resultado de la aplicación de la llamada cláusula catch-all (artículo 4 del Reglamento CE n 428/2009).
El uso de la cláusula catch-all por las autoridades españolas significa que las operaciones son estudiadas detenidamente y no quiere decir que las licencias vayan a ser denegadas automáticamente. De hecho, la mayoría de estas operaciones han sido autorizadas después de ser sometidas a control.

Los envíos consistieron en válvulas en acero inoxidable, con repuestos, para las industrias de generación de energía, petroquímica, de tratamiento de aguas, del petróleo y del gas, tubos y colectores para un horno industrial en la producción de fertilizantes, así como conjuntos para hornos industriales en acerías.

La RP China fue el tercer destino más significativo, con 23,3 millones de euros y un 13,8 por 100 , distribuidos en vehículos aéreos no tripulados destinados a la fumigación en el sector agrícola y para cartografía, circuitos integrados al sector de telecomunicaciones y a satélites, sensores de infrarrojos para la monitorización de soldaduras industriales, amplificadores de microondas destinados a sistemas de alarmas de trenes y a un satélite, condensadores eléctricos para los sectores del transporte ferroviario y de energía, diez máquinas-herramienta a los sectores aeronáutico, de mecanizado de piezas y moldes industriales, automoción y militar (artillería), sistemas de control numérico destinados a máquinas-herramienta en los sectores de automoción, de la enseñanza, de la mecanización de relojes, de azulejos y del mecanizado de moldes y recipientes a presión, así como válvulas en acero inoxidable al sector petroquímico.

Es importante señalar que los envíos a Rusia $(14,4$ millones de euros y un 8,5 por 100$)$ se realizaron, en parte, antes de la imposición de las sanciones por parte de la Unión Europea, y en otro montante acogiéndose a las exenciones previstas en las mismas.

Los envíos consistieron en un satélite de observación terrestre, condensadores eléctricos para el transporte ferroviario, circuitos integrados para una estación espacial y el sector de telecomunicaciones, doce máquinas-herramienta con destino a los sectores aeronáutico, de generación de energía, del $\triangleright$ 
petróleo, alimentario y de automoción, además de sustancias químicas para su uso en una planta de energía, en laboratorios y en la industria farmacéutica.

Al margen de los diez principales destinos incluidos en el cuadro anterior, el porcentaje restante $(15,4$ por 100$)$ estuvo muy distribuido entre cincuenta y dos países de diversas áreas.

En el año 2014, las ventas se concentraron fundamentalmente en la categoría de «tratamiento de los materiales» $(101,1$ millones de euros, $60,0$ por 100$)$.

Las exportaciones realizadas representaron un 80,4 por 100 de las operaciones autorizadas, ascendiendo éstas a 209,5 millones de euros.

\subsection{Denegaciones, suspensiones y revocaciones}

En el ámbito del doble uso hubo tres operaciones de exportación denegadas, con el siguiente desglose:

- Una licencia de exportación a Irán de una válvula en acero al carbono para la industria del gas al estar incluido el usuario final en el Reglamento de Ejecución (UE) n 945/2012, de 15 de octubre, por el que se aplica el Reglamento (UE) $n^{\circ} 267 / 2012$, de 23 de marzo, relativo a medidas restrictivas contra Irán.

- Una licencia de exportación a Rusia de una máquina de electroerosión por riesgo de desvío a un programa de misiles.

- Una licencia de exportación a India de un centro de mecanizado por la existencia de una denegación esencialmente idéntica de un país de la UE alegando riesgo de desvío a un programa nuclear.

Fueron renovadas diez denegaciones en el Grupo Australia. En el seno del Régimen de Control de la Tecnología de Misiles y del Grupo de Suministradores Nucleares se decidió renovar dos y tres denegaciones, respectivamente. Se revocó una denegación en el Arreglo de Wassenaar.
Por último, cabe decir que la cláusula catchall fue aplicada en cinco casos, consistentes en dos posibles exportaciones a Irán de tubos de válvulas en acero inoxidable con destino a la industria petroquímica, una exportación a Rusia de un centro de fresado, una exportación a Sudán de repuestos para máquinas-herramienta y un envío a Bielorrusia de una máquina de electroerosión.

Por parte de la Unión Europea, se adoptaron sanciones a Rusia el 31 de julio de 2014, consistentes en un embargo a la exportación de productos y tecnologías de doble uso con un uso o usuario final militar (Decisión 2014/512/PESC y el Reglamento UE n $833 / 2014$ del Consejo, de 31 de julio).

El 8 de septiembre se añadieron nuevas sanciones (Decisión 2014/659/PESC y el Reglamento UE n' 960/2014 del Consejo, de 8 de septiembre). Los cambios afectaron a la vertiente de doble uso y se tradujeron en la introducción de una segunda prohibición basada en no poder exportar a una lista de nueve entidades con actividades militares, no aplicándose al sector aeronáutico civil y a la industria espacial para un uso final y usuario final no militares. Asimismo, se estableció una cláusula de salvaguardia para esta nueva prohibición, tal y como se había hecho con la anterior (1 de agosto de 2014), relativa a los contratos o acuerdos celebrados antes de la fecha de entrada en vigor de las sanciones (12 de septiembre de 2014).

Durante 2014, y en el ámbito de las operaciones de doble uso, se colaboró en una investigación llevada a cabo por un país miembro de los foros internacionales de no proliferación relativa a posibles exportaciones a Irán por parte de tres empresas españolas de productos destinados a refinerías de petróleo propiedad de entidades sancionadas por dicho país.

El informe anual de estadísticas se puede consultar en la página de Internet de la Secretaría de Estado de Comercio: www.comercio.gob.es $\quad \square$ 


\section{Anexo estadístico}

\begin{tabular}{|c|c|c|c|c|c|}
\hline País & $\begin{array}{l}\text { Número } \\
\text { licencias }\end{array}$ & $\begin{array}{l}\text { Valor } \\
\text { euros }\end{array}$ & País & $\begin{array}{l}\text { Número } \\
\text { Licencias }\end{array}$ & $\begin{array}{l}\text { Valor } \\
\text { euros }\end{array}$ \\
\hline Afganistán .. & 1 & 38.820 & Israel . & 20 & 19.461 .750 \\
\hline Alemania & 110 & 338.969 .963 & 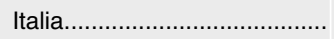 & 83 & 160.452 .370 \\
\hline 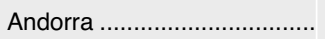 & 17 & 249.077 & 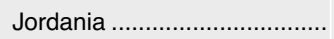 & 3 & 10.000 .000 \\
\hline Angola .............................. & 2 & 964.260 & 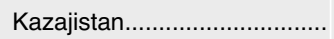 & 2 & 83.300 .000 \\
\hline Arabia Saudí ............................ & 11 & 68.903 .510 & Kenia .................................. & 1 & 748.250 \\
\hline Argelia ............................ & 2 & 419.848 & 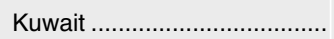 & 3 & 1.392 .800 \\
\hline 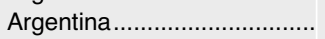 & 13 & 2.547 .960 & Letonia ............................... & 1 & 0 \\
\hline Australia .............................. & 12 & 523.707 .618 & Libia..................................... & 2 & 953.620 \\
\hline Austria ............................ & 15 & 33.806 .444 & Lituania...................................... & 1 & 0 \\
\hline Bahrein & 7 & 25.171 .440 & Luxemburgo ........................... & 10 & 20.151 .760 \\
\hline 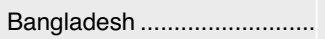 & 3 & 710 & 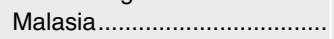 & 11 & 6.864 .230 \\
\hline 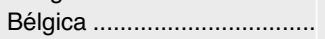 & 34 & 48.955 .583 & Marruecos ............................. & 9 & 31.946 .928 \\
\hline 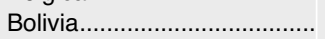 & 1 & 30.000 .000 & Mauritania ................................ & 1 & 0 \\
\hline 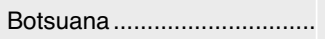 & 2 & 30.000 .000 & 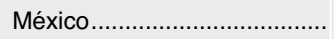 & 8 & 200.035 .818 \\
\hline 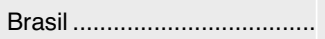 & 30 & 290.923 .264 & 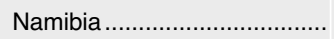 & 1 & 0 \\
\hline 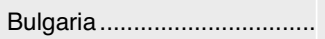 & 5 & 169.408 & 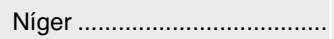 & 3 & 1.152 .709 \\
\hline Burkina Faso .......................... & 2 & 578 & 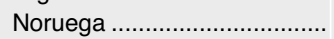 & 17 & 2.018 .916 \\
\hline 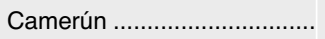 & 2 & 1.419 .292 & Nueva Zelanda....................... & 1 & 1.240 .000 \\
\hline 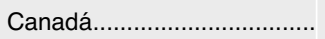 & 16 & 5.729 .433 & 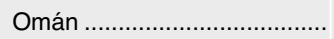 & 5 & 85.221 .810 \\
\hline Catar .............................. & 4 & 201.249 & Países Bajos ............................ & 11 & 676.155 \\
\hline 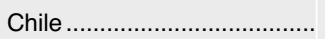 & 23 & 32.815 .757 & 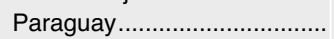 & 3 & 40.001 .000 \\
\hline Colombia .......................... & 6 & 13.807 .321 & 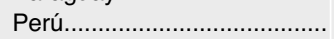 & 8 & 2.720 .527 \\
\hline Corea del Sur......................... & 4 & 41.554 .430 & 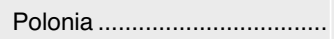 & 13 & 5.697 .435 \\
\hline 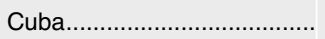 & 5 & 223.719 & Portugal................................ & 40 & 4.919 .021 \\
\hline Dinamarca ............................ & 16 & 4.314 .147 & Reino Unido ........................... & 74 & 282.379 .091 \\
\hline 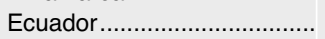 & 5 & 145.051 .300 & Rep. Checa .............................. & 6 & 3.858 .405 \\
\hline Egipto & 13 & 182.406 .374 & 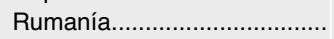 & 2 & 2.806 \\
\hline Emiratos Árabes Unidos ....... & 5 & 10.000 .000 & 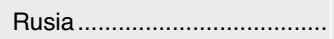 & 1 & 442.400 \\
\hline 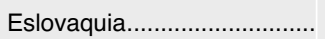 & 2 & 6.800 & 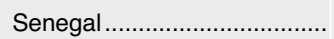 & 1 & 70.560 \\
\hline 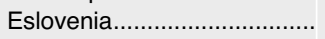 & 2 & 635.690 & 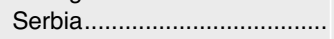 & 2 & 2.200 .000 \\
\hline 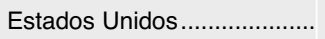 & 205 & 100.486 .159 & Seychelles................................ & 3 & 11.730 \\
\hline 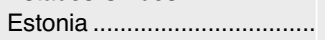 & 1 & 0 & 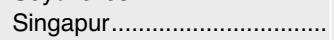 & 2 & 658.219 \\
\hline 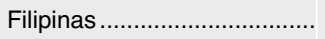 & 1 & 120.000 .000 & 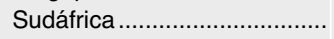 & 7 & 60.000 .000 \\
\hline 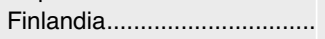 & 3 & 2.200 .000 & Suecia & 9 & 2.487 .254 \\
\hline 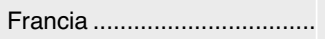 & 126 & 143.325 .508 & Suiza .................................. & 17 & 3.169 .999 \\
\hline Grecia & 6 & 48.453 .156 & 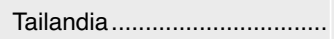 & 12 & 3.800 .347 \\
\hline Groenlandia (Dinamarca)..... & 1 & 19.360 .000 & 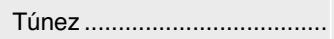 & 2 & 1.612 .950 \\
\hline 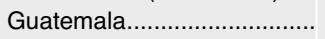 & 1 & 680.163 & 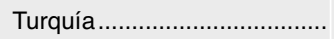 & 21 & 61.774 .783 \\
\hline 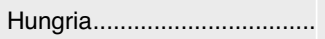 & 4 & 386.790 & Ucrania............................. & 1 & 11.000 \\
\hline India & 19 & 8.910 .143 & 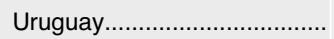 & 9 & 22.765 .611 \\
\hline Indonesia .............................. & 11 & 23.202 .112 & Venezuela ............................. & 2 & 29.000 .000 \\
\hline Irak & 8 & 95.850 .482 & Vietnam & 2 & 113.253 .000 \\
\hline $\begin{array}{l}\text { Irlanda } \\
\text { Islandia }\end{array}$ & $\begin{array}{l}3 \\
1\end{array}$ & $\begin{array}{r}4.100 .000 \\
0\end{array}$ & Total ... & 1.190 & 3.666 .401 .762 \\
\hline
\end{tabular}

Fuente: Subdirección General de Comercio Internacional de Material de Defensa y Doble Uso. Ministerio de Economía y Competitividad. 


\section{Subdirección General de Comercio Internacional de Material de Defensa y Doble Uso}

\begin{tabular}{|c|c|c|c|c|c|c|c|c|c|c|c|}
\hline \multicolumn{12}{|c|}{$\begin{array}{l}\text { 2. EXPORTACIONES AUTORIZADAS DE MATERIAL DE DEFENSA POR PAÍSES Y ARTÍCULOS DE PRODUCTOS } \\
2014\end{array}$} \\
\hline \multirow{2}{*}{ País } & \multicolumn{11}{|c|}{ Artículos y valor en euros } \\
\hline & 1 & 2 & 3 & 4 & 5 & 6 & 7 & 8 & 9 & 10 & 11 \\
\hline Afganistán ............................. & & & & & 38.820 & & & & & & \\
\hline 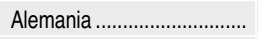 & 1.379 .540 & & 2.233 .665 & 10.523 .589 & & 680.441 & & 0 & 0 & 291.817 .041 & 32.335 .687 \\
\hline Andorra ................................. & 239.946 & & 9.131 & & & & & & & & \\
\hline Angola & 666.000 & & 298.260 & & & & & & & & \\
\hline Arabia Saudí ......................... & 2.760 & & 41.700 .750 & & & & & & & 23.200 .000 & 4.000 .000 \\
\hline Argelia & & 0 & & & 419.848 & & & & & & \\
\hline Argentina ............................. & 27.460 & & 520.500 & & & & & & & 2.000 .000 & \\
\hline Australia ............................. & 32.000 & & 1.100 .000 & 145.000 & & & & & 278.430 .618 & 20.000 .000 & \\
\hline Austria .................................. & 23.100 & 8.144 & 1.222 .900 & & & 282.017 & & & & 32.200 .000 & \\
\hline 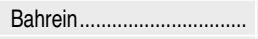 & 60.000 & 2.400 & 5.209 .040 & & & 19.900 .000 & & & & & \\
\hline Bangladesh ........................... & 710 & & 0 & & & & & & & & \\
\hline Bélgica ................................ & 1.239 .402 & 31.519 & 7.684 .638 & & & & & & & 40.000 .024 & \\
\hline 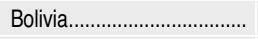 & & & & & & & & & & 30.000 .000 & \\
\hline 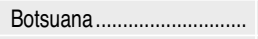 & & & & & & & & & & 30.000 .000 & \\
\hline Brasil .................................... & 7.817 & & 135.640 & 511.091 & & 15.507 & & & 17.300 .000 & 258.472 .015 & 604.264 \\
\hline 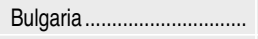 & & & & & & & & 169.408 & & & \\
\hline Burkina Faso ......................... & 578 & & & & & & & & & 0 & \\
\hline Camerún & & 748.192 & 671.100 & & & & & & & & \\
\hline 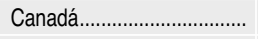 & & & & 15.973 & & 3.182 .708 & & 289.462 & & 2.206 .472 & 34.818 \\
\hline Catar ................................... & & & & & & 201.249 & & & & & \\
\hline 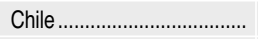 & & 0 & 2.551 .144 & 33.334 & & 206.270 & & & 25.009 & 30.000 .000 & \\
\hline Colombia & & & 307.321 & & & & & & & 13.500 .000 & 0 \\
\hline Corea del Sur......................... & & & & & & & & 1.500 .000 & & 30.000 .000 & 6.062 .328 \\
\hline Cuba................................ & 210.783 & & 12.936 & & & & & & & & \\
\hline 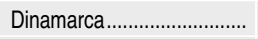 & 1.100 .000 & 3.959 & 1.040 .000 & 1.190 .188 & & 0 & & 980.000 & & 0 & \\
\hline 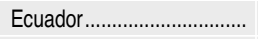 & & & & 51.300 & & & & & & 145.000 .000 & \\
\hline Egipto & 1.675 & & & & & 2.404 .699 & & & & 180.000 .000 & \\
\hline Emir. Árabes Unidos ............ & 0 & & & & & 0 & & & & 10.000 .000 & \\
\hline 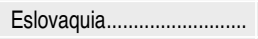 & 6.800 & & & & & & & & & & \\
\hline Eslovenia................................. & & & 459.940 & & & & & 175.750 & & & \\
\hline Estados Unidos ...................... & 58.476 .659 & 234.267 & 3.196 .812 & & 7.378 .000 & 0 & & 1.800 .000 & 0 & 10.762 .599 & 18.312 .702 \\
\hline \multicolumn{12}{|l|}{ Estonia } \\
\hline 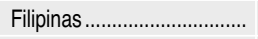 & & & & & & & & & & 120.000 .000 & \\
\hline 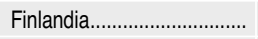 & 2.200 .000 & & & & & & & & & 0 & \\
\hline Francia .................................. & 1.104 .043 & 0 & 250.228 & 4.148 .339 & & 0 & & 11.284 .759 & 0 & 119.973 .493 & 6.495 .746 \\
\hline Grecia................................. & & & & & & & & 48.353 .156 & & & \\
\hline Groenlandia (Dinamarca)... & & & & & & & & 19.360 .000 & & & \\
\hline \multicolumn{12}{|l|}{ Guatemala } \\
\hline Hungría .................................. & & & 381.790 & & & & & & & 0 & \\
\hline India & & & & 0 & & & & & 1.674 .840 & 120.000 & 6.691 .345 \\
\hline 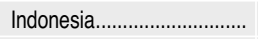 & & 0 & 331.100 & & & & & & & 22.527 .012 & \\
\hline Irak & & & 76.415 .217 & 139.007 & & 19.296 .258 & & & & & \\
\hline Irlanda & & & 600.000 & & & & & & & 3.500 .000 & \\
\hline 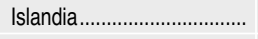 & & & & & & & & & & 0 & \\
\hline 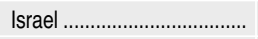 & & & & & & 0 & & & & 0 & 96.750 \\
\hline 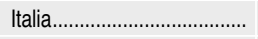 & 1.444 .800 & 1.579 .380 & 2.988 .527 & 256.024 & & 3.564 .480 & & 40.676 .865 & 1.033 .324 & 104.269 .237 & 719.825 \\
\hline 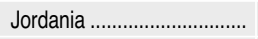 & & & & & & & & & & 10.000 .000 & \\
\hline Kazajistán............................... & & & & & & & & & & 65.000 .000 & \\
\hline Kenia & & & 748.250 & & & & & & & & \\
\hline Kuwait .................................. & & & 1.392 .800 & & & & & & & & \\
\hline Letonia & & & & & & & & & & 0 & \\
\hline 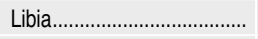 & & & & & & & 843.150 & & & & \\
\hline 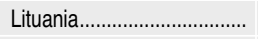 & & & & & & & & & & 0 & \\
\hline Luxemburgo ........................ & & & 151.760 & 0 & & & & & & 20.000 .000 & \\
\hline 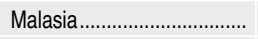 & & 0 & 6.482 .780 & & & & & 232.250 & & & \\
\hline Marruecos ........................... & & & 24.159 .248 & & & & & 787.680 & & 7.000 .000 & \\
\hline Mauritania ........................... & 0 & & & & & & & & & & \\
\hline
\end{tabular}


ESTADÍSTICAS DE LAS EXPORTACIONES ESPAÑOLAS DE MATERIAL DE DEFENSA...

2. EXPORTACIONES AUTORIZADAS DE MATERIAL DE DEFENSA POR PAÍSES Y ARTÍCULOS DE PRODUCTOS 2014 (continuación)

\begin{tabular}{|c|c|c|c|c|c|c|c|c|c|c|c|}
\hline \multirow{2}{*}{ País } & \multicolumn{11}{|c|}{ Artículos y valor en euros } \\
\hline & 1 & 2 & 3 & 4 & 5 & 6 & 7 & 8 & 9 & 10 & 11 \\
\hline México .................................... & 15.818 & & & & & & & & & 200.020 .000 & \\
\hline 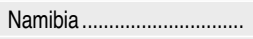 & 0 & & & & & & & & & & \\
\hline Níger & & & & & & & & & & 0 & \\
\hline 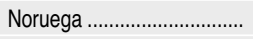 & 45.000 & & 1.606 .416 & & & & & 367.500 & & 0 & \\
\hline Nueva Zelanda................... & & & 1.240 .000 & & & & & & & & \\
\hline 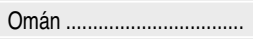 & & & 1.438 .400 & & & 0 & & 33.410 & & & \\
\hline 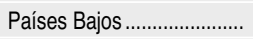 & & & & 118.000 & & 0 & & & 245.655 & 0 & 0 \\
\hline 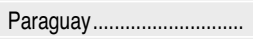 & & & 1.000 & & & & & & & 40.000 .000 & \\
\hline 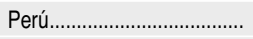 & & & 1.231 .462 & 1.394 .945 & & 0 & & & & 94.120 & 0 \\
\hline 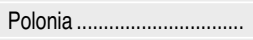 & 16.580 & & 1.048 .980 & & & 0 & & 76.670 & & 3.500 .000 & 1.055 .205 \\
\hline 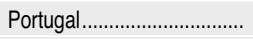 & 640.044 & 6.604 & 1.534 .000 & 672.000 & & 0 & & 667.497 & & 1.398 .876 & \\
\hline 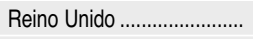 & 327.646 & 0 & 778.700 & 28.521 .540 & & 0 & & & 9.607 & 225.349 .399 & 27.387 .291 \\
\hline Rep. Checa .......................... & 367.500 & & 3.490 .905 & & & & & & & & \\
\hline 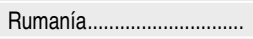 & 150 & & & & & 2.656 & & & & & \\
\hline 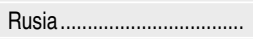 & 442.400 & & & & & & & & & & \\
\hline 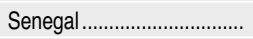 & 70.560 & & & & & & & & & & \\
\hline 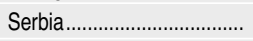 & 2.200 .000 & & & & & & & & & & \\
\hline 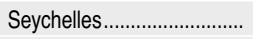 & 0 & & 11.730 & & & & & & & & \\
\hline 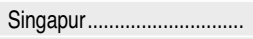 & & & & 302.720 & & 355.499 & & & & & \\
\hline Sudáfrica ................................ & 0 & & & & & & & & & 60.000 .000 & 0 \\
\hline 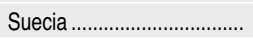 & 13.800 & & & & & & & & & 0 & 0 \\
\hline Suiza & 0 & 3.084 .699 & 42.066 & & & 43.234 & & & & 0 & 0 \\
\hline 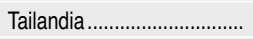 & & & 1.981 .353 & 0 & 460.460 & 409.123 & & 38.400 & & & 94.000 \\
\hline Túnez & & & & 1.221 .600 & & & & & & & \\
\hline 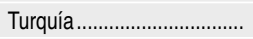 & & & & & & 27.680 .080 & 60.000 & & 2.660 .419 & 24.500 .000 & 6.874 .284 \\
\hline 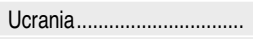 & 11.000 & & & & & & & & & & \\
\hline 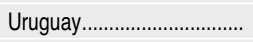 & & 271.168 & 1.031 .685 & 0 & & & & & & 20.000 .000 & 1.041 .000 \\
\hline 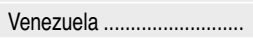 & & & & & & 20.000 .000 & & & & 9.000 .000 & \\
\hline 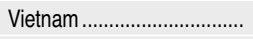 & & & & & 18.253 .000 & & & & & 95.000 .000 & \\
\hline Total ...................................... & 72.374 .571 & 5.970 .332 & 197.692 .174 & 49.244 .650 & 26.550 .128 & 98.224 .221 & 903.150 & 126.792 .807 & 301.379 .472 & 2.300 .410 .288 & 111.805 .245 \\
\hline
\end{tabular}




\section{Subdirección General de Comercio Internacional de Material de Defensa y Doble Uso}

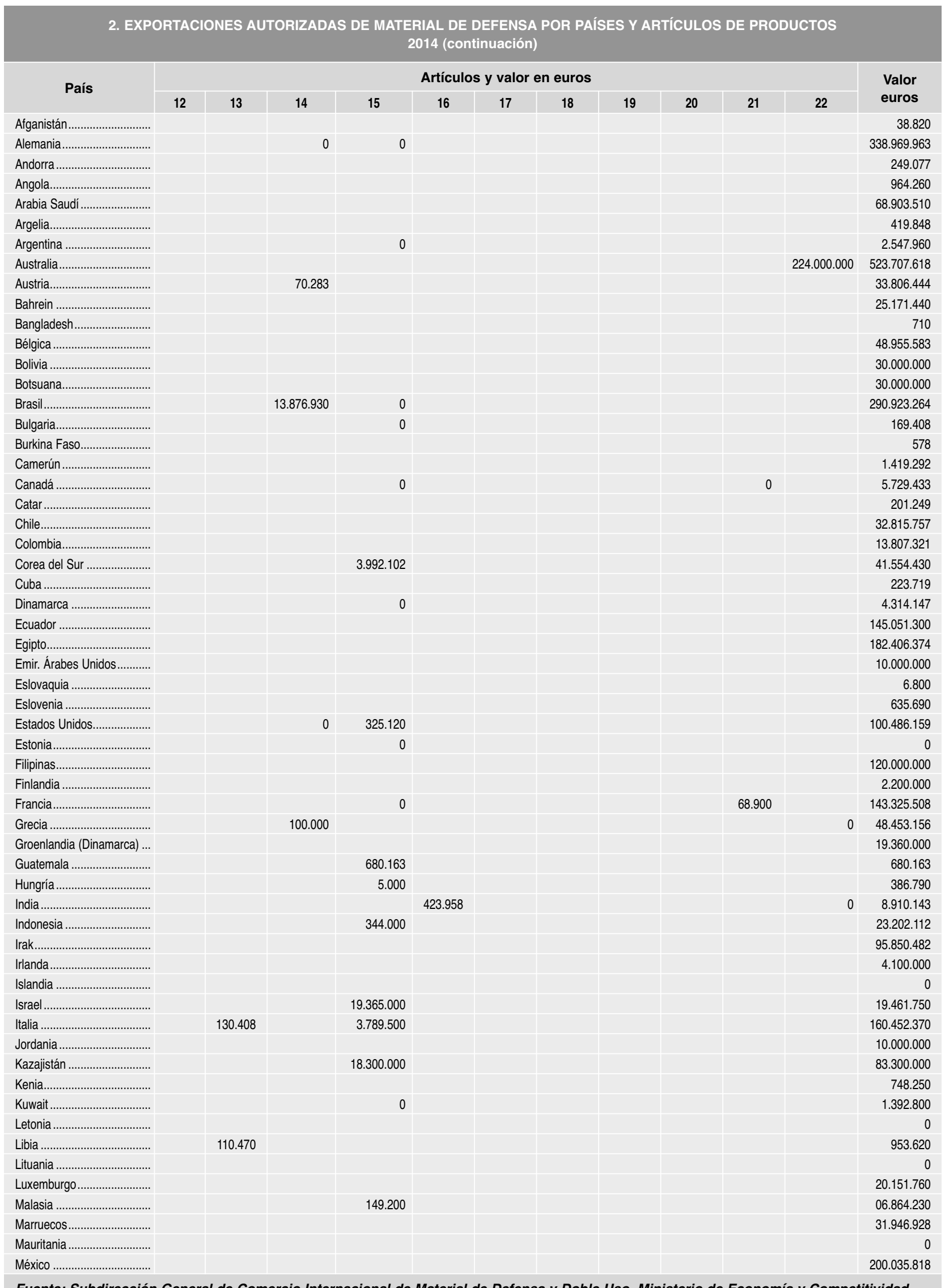

Fuente: Subdirección General de Comercio Internacional de Material de Defensa y Doble Uso. Ministerio de Economía y Competitividad. 
ESTADÍSTICAS DE LAS EXPORTACIONES ESPAÑOLAS DE MATERIAL DE DEFENSA...

\begin{tabular}{|c|c|c|c|c|c|c|c|c|c|c|c|c|}
\hline \multirow{2}{*}{ País } & \multicolumn{11}{|c|}{ Artículos y valor en euros } & \multirow{2}{*}{$\begin{array}{l}\text { Valor } \\
\text { euros }\end{array}$} \\
\hline & 12 & 13 & 14 & 15 & 16 & 17 & 18 & 19 & 20 & 21 & 22 & \\
\hline 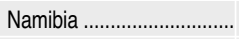 & & & & & & & & & & & & 0 \\
\hline 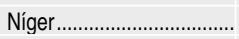 & & & & 1.152 .709 & & & & & & & & 1.152 .709 \\
\hline Noruega............................. & & & 0 & & & & & & & & 0 & 2.018 .916 \\
\hline Nueva Zelanda .................. & & & & & & & & & & & & 1.240 .000 \\
\hline 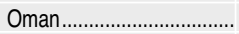 & & & & 83.750 .000 & & & & & & & & 85.221 .810 \\
\hline Países Bajos....................... & & & & 312.500 & & & & & & & & 676.155 \\
\hline Paraguay .............................. & & & & & & & & & & & & 40.001 .000 \\
\hline 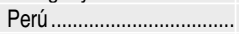 & & & & & & & & & & & & 2.720 .527 \\
\hline Polonia................................... & & & & & & & & & & & & 5.697 .435 \\
\hline Portugal .............................. & & & & & & & & & & & 0 & 4.919 .021 \\
\hline 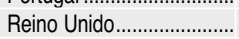 & & & & 4.800 & & & & & & 108 & 0 & 282.379.091 \\
\hline Rep. Checa........................ & & & & & & & & & & & & 3.858 .405 \\
\hline 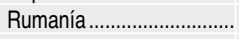 & & & & & & & & & & & & 2.806 \\
\hline Rusia .............................. & & & & & & & & & & & & 442.400 \\
\hline 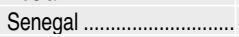 & & & & & & & & & & & & 70.560 \\
\hline 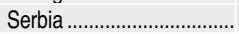 & & & & & & & & & & & & 2.200 .000 \\
\hline 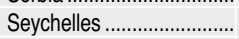 & & & & & & & & & & & & 11.730 \\
\hline 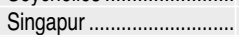 & & & & & & & & & & & & 658.219 \\
\hline 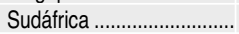 & & & 0 & 0 & & & & & & & & 60.000 .000 \\
\hline 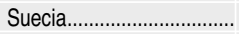 & & 2.468 .654 & 0 & 4.800 & & & & & & & & 2.487 .254 \\
\hline 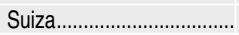 & & & & 0 & & & & & & 0 & & 3.169 .999 \\
\hline 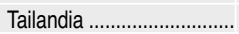 & & & & 817.011 & & & & & & & & 3.800 .347 \\
\hline 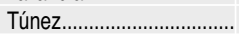 & & 391.350 & & & & & & & & & & 1.612 .950 \\
\hline 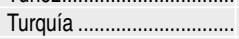 & & & & & & & & & & & & 61.774 .783 \\
\hline Ucrania & & & & & & & & & & & & 11.000 \\
\hline 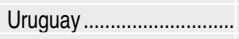 & & & & 421.758 & & & & & & & & 22.765 .611 \\
\hline 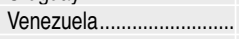 & & & & & & & & & & & & 29.000 .000 \\
\hline 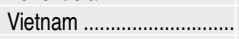 & & & & & & & & & & & & 113.253 .000 \\
\hline 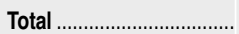 & & 3.100 .882 & 14.047.213 & 133.413 .663 & 423.958 & & & & & 69.008 & 224.000 .000 & 3.666 .401 .762 \\
\hline
\end{tabular}

Fuente: Subdirección General de Comercio Internacional de Material de Defensa y Doble Uso. Ministerio de Economía y Competitividad. 


\section{Subdirección General de Comercio Internacional de Material de Defensa y Doble Uso}

\begin{tabular}{|c|c|c|c|c|c|c|c|c|c|c|c|}
\hline \multirow{2}{*}{ País } & \multicolumn{11}{|c|}{ Artículos y valor en euros } \\
\hline & 1 & 2 & 3 & 4 & 5 & 6 & 7 & 8 & 9 & 10 & 11 \\
\hline 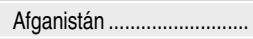 & & & & & 51.756 & & & & & & 463.485 \\
\hline 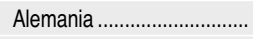 & 618.770 & & 2.160 .165 & 6.465 .625 & & 284.969 & & 0 & & 255.909 .308 & 2.545 .110 \\
\hline 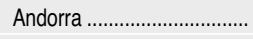 & 17.566 & & 7.044 & & & & & & & & \\
\hline Arabia Saudí ..................... & 620 & & 30.157 .111 & 5.010 .000 & & & & & & 256.378 .629 & 680.000 \\
\hline 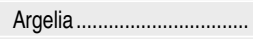 & & 0 & & & 419.848 & & & & & & \\
\hline Argentina............................. & 28.970 & & 520.500 & & & & & & & & \\
\hline Australia ............................. & & & 1.100 .000 & & & & & & 132.565 .733 & 126.899 & 5.895 .930 \\
\hline 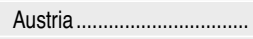 & 9.059 & & 1.222 .901 & & & 4.454 & & & & 281.737 & \\
\hline 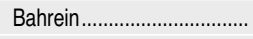 & & 0 & 13.249 .360 & 26.622 .200 & & & & & & & \\
\hline 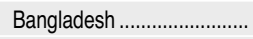 & 710 & & & & & & & & & & \\
\hline 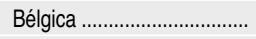 & 165.987 & 31.519 & 3.277 .161 & 3.707 .242 & & & & & & 66.500 & \\
\hline 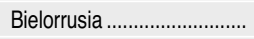 & & & & & & & & 0 & & & \\
\hline 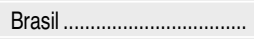 & 2.634 & & 412.911 & 511.091 & & 15.507 & & & 313.716 & 27.473 .047 & 107.034 \\
\hline 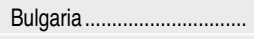 & 4.335 & & & & & & & 48.177 & & & 580.591 \\
\hline 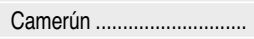 & & & & & & & & & 11.932 .225 & 2.210 .951 & \\
\hline 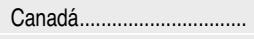 & & & & 423.518 & & 2.400 .395 & & & & 476.394 & 10.484 \\
\hline 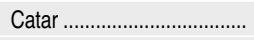 & & & & & & 666.772 & & & & & \\
\hline 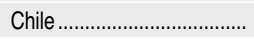 & & & 8.478 .983 & 33.334 & & 3.549 & & & 25.009 & 1.066 .428 & \\
\hline Colombia & & & 307.321 & 851.127 & & & & & & 550.708 & \\
\hline Cuba...................................... & 129.183 & & & & & & & & & & \\
\hline 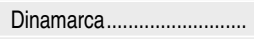 & 24.550 & 3.959 & 977.280 & 1.190 .188 & & & & 137.020 & & 0 & \\
\hline 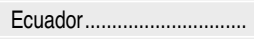 & & & & 102.600 & & & & & & 85.818 .670 & \\
\hline Egipto & 1.675 & & & & & 1.967 .685 & & & & 105.981 .689 & \\
\hline Eslovaquia........................... & 6.800 & & & & & & & & & & \\
\hline Eslovenia................................ & 480 & & 459.940 & & & & & 175.750 & & & \\
\hline Estados Unidos ..................... & 17.590 .833 & 8.500 & 798.932 & & 996.861 & 491.925 & & 31.394 & 100 & 3.815 .297 & 10.291.377 \\
\hline Finlandia................................. & 13.534 & & & & & & & & & 666.191 & \\
\hline Francia & 97.114 & & 51.936 & 1.148 .670 & & & & 17.077 .863 & & 496.838 .330 & 5.006 .101 \\
\hline Ghana & & & & & & & & & & 342.735 & \\
\hline Grecia................................... & 980 & & & & & & & 47.442 .867 & & & \\
\hline Groenlandia (Dinamarca)... & & & & & & & & 19.786 .739 & & & \\
\hline \multicolumn{12}{|l|}{ 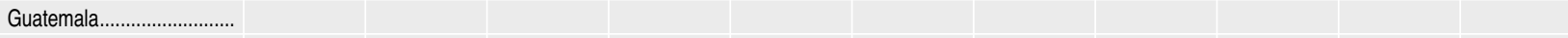 } \\
\hline Hungría ................................. & & & 381.790 & & & & & & & & \\
\hline India .......................................... & & & & 690.235 & & & & & 3.326 .721 & 20.812 & 10.521 .713 \\
\hline 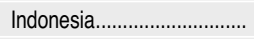 & & 2.019 .454 & & & 249.972 & & & & & 109.517 .152 & \\
\hline Irlanda & & & 600.000 & & & & & & & & \\
\hline 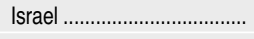 & 119.125 & & & 2.224 .602 & & & & & & & 135.400 \\
\hline Italia & 116.099 & 6.702 .747 & 2.234 .096 & 303.184 & & 64.200 & & 25.247 .196 & 814.218 & 55.459 .237 & 641.450 \\
\hline 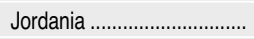 & & & & & & & & & & 190.209 & \\
\hline Kazajistán............................... & 3.142 & & & & & & & & & 53.892 .411 & \\
\hline Kenia ..................................... & & & 748.250 & & & & & & & & \\
\hline Kuwait & & & 817.800 & & & & & & & & \\
\hline Letonia & & & 597.550 & & & & & & & & \\
\hline 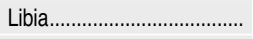 & & & & & & & 168.630 & & & & \\
\hline Luxemburgo ........................ & & & 151.760 & 0 & & & & & & & \\
\hline 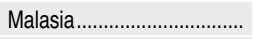 & & & 1.293 .229 & & & & & 232.250 & & & \\
\hline Marruecos ............................. & & & 9.702 .553 & & & & & & & & \\
\hline Mauritania ............................ & 0 & & & & & & & & & & \\
\hline México & & & & & & & & & & 78.537 & \\
\hline Namibia & 0 & & & & & & & & & & \\
\hline Noruega ................................. & 22.545 & & 1.515 .531 & & & & & 481.550 & & & \\
\hline Nueva Zelanda........................ & 18.260 & & & 430.000 & & & & & & & \\
\hline Omán & & & 2.828 .900 & 6.259 .000 & & & & 33.410 & & 55.772 .171 & \\
\hline Países Bajos ........................... & & & & 118.000 & & & & & 245.655 & 0 & 38.850 \\
\hline Pakistán .............................. & & & & & & 318.305 & & & & & 106.162 \\
\hline Perú................................... & & & 1.231 .462 & 1.604 .116 & & & & & & & \\
\hline 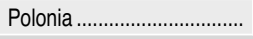 & 16.580 & & 785.860 & & & & & 800 & & & \\
\hline
\end{tabular}


ESTADÍSTICAS DE LAS EXPORTACIONES ESPAÑOLAS DE MATERIAL DE DEFENSA...

3. EXPORTACIONES REALIZADAS DE MATERIAL DE DEFENSA POR PAISES Y ARTÍCULOS DE PRODUCTOS 2014 (continuación)

\begin{tabular}{|c|c|c|c|c|c|c|c|c|c|c|c|}
\hline \multirow{2}{*}{ País } & \multicolumn{11}{|c|}{ Artículos y valor en euros } \\
\hline & 1 & 2 & 3 & 4 & 5 & 6 & 7 & 8 & 9 & 10 & 11 \\
\hline Portugal................................. & 229.921 & & 1.768 .000 & 955.500 & & & & 420.948 & & 97.913 & \\
\hline Reino Unido .......................... & 73.600 & & 361.400 & 17.881 .322 & & 4.466 & & & 9.607 & 809.251 .066 & 5.360 .119 \\
\hline Rep. Checa ........................... & 18.350 & & 1.806 .030 & & & & & & & 38.838 & \\
\hline Rumania.............................. & 150 & & & & & & & & & & \\
\hline Rusia ................................ & 6.865 & & & & & & & & & & \\
\hline Serbia & 10.265 & & & & & & & & & & \\
\hline Seychelles............................. & & & 11.730 & & & & & & & & \\
\hline Singapur............................... & & & & 302.720 & & 2.027 .371 & & & & & \\
\hline 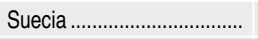 & 11.180 & & & 66.000 & & & & & & 0 & 7.548 .876 \\
\hline Suiza ................................... & 29.200 & 1.660 .749 & 29.258 & & & 13.761 & & & & 0 & \\
\hline Tailandia ............................... & & & 1.534 .582 & 0 & 501.851 & 409.123 & & 38.400 & & & 94.000 \\
\hline Tanzania............................. & 33.000 & & & & & & & & & & \\
\hline Túnez ………………….... & & & & 1.221 .600 & & & & & & & \\
\hline Turquía ................................ & & & & & & & 27.500 & & 3.582 .029 & 240.063 .965 & \\
\hline Uruguay............................... & & & 712.885 & & & & & & & 7.061 & \\
\hline 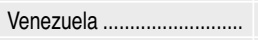 & & 2.863 .342 & & & & 361.877 & & & 4.065 .003 & & \\
\hline Vietnam & & & & & & & & & & 36.491 .579 & \\
\hline Zambia .................................. & 7.382 & & 744 & & & & & & & & \\
\hline Total .................................... & 19.429 .464 & 13.290 .270 & 92.294 .955 & 78.121 .874 & 2.220 .288 & 9.034 .359 & 196.130 & 111.154.364 & 156.880 .015 & 2.598 .884 .464 & 50.026 .682 \\
\hline
\end{tabular}

Fuente: Departamento de Aduanas e IIEE (Ministerio de Hacienda y AAPP) y empresas exportadoras. Elaboración: Subdirección General de Comercio Internacional de Material de Defensa y Doble Uso. Ministerio de Economía y Competitividad. 


\section{Subdirección General de Comercio Internacional de Material de Defensa y Doble Uso}

3. EXPORTACIONES REALIZADAS DE MATERIAL DE DEFENSA POR PAÍSES Y ARTÍCULOS DE PRODUCTOS 2014 (continuación)

\begin{tabular}{|c|c|c|c|c|c|c|c|c|c|c|c|c|}
\hline \multirow{2}{*}{ País } & \multicolumn{11}{|c|}{ Artículos y valor en euros } & \multirow{2}{*}{$\begin{array}{l}\text { Valor } \\
\text { euros }\end{array}$} \\
\hline & 12 & 13 & 14 & 15 & 16 & 17 & 18 & 19 & 20 & 21 & 22 & \\
\hline Afganistán ............................. & & & & 57.345 & & & & & & & & 572.586 \\
\hline Alemania & & & & 4.465 .001 & & & & & & & & 272.448 .948 \\
\hline Andorra ................................ & & & & & & & & & & & & 24.610 \\
\hline Arabia Saudí ……………......... & & & 2.846 & 632.583 & & & & & & & & 292.861 .789 \\
\hline Argelia & & & & & & & & & & & & 419.848 \\
\hline 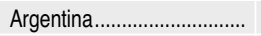 & & & & 0 & & & & & & & & 549.470 \\
\hline Australia ............................. & & & & & & & & & & & & 139.688 .562 \\
\hline 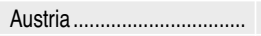 & & & 50.000 & & & & & & & & & 1.568 .151 \\
\hline Bahrein .................................. & & & & & 60.000 & & & & & & & 39.931 .560 \\
\hline Bangladesh ............................... & & & & & & & & & & & & 710 \\
\hline Bélgica .................................. & & & & & & & & & & & & 7.248 .409 \\
\hline Bielorrusia ............................. & & & & & & & & & & & & 0 \\
\hline 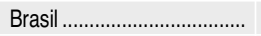 & & & 31.137 & & & & & & & & & 28.867.077 \\
\hline Bulgaria ............................. & & & & & & & & & & & & 633.103 \\
\hline Camerún ……………............ & & & & 14.379.729 & & & & & & & & 28.522 .905 \\
\hline Canadá & & & & & & & & & & & & 3.310 .791 \\
\hline 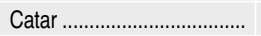 & & & & & & & & & & & & 666.772 \\
\hline Chile ................................ & & & & & & & & & & & & 9.607 .303 \\
\hline Colombia …………….......... & & & & & & & & & & & & 1.709 .156 \\
\hline Cuba & & & & & & & & & & & & 129.183 \\
\hline Dinamarca............................. & & & & & & & & & & & & 2.332 .997 \\
\hline Ecuador ............................... & & & & & & & & & & & & 85.921 .270 \\
\hline Egipto & & & & & & & & & & & & 107.951 .049 \\
\hline Eslovaquia.............................. & & & & & & & & & & & & 6.800 \\
\hline Eslovenia................................... & & & & & & & & & & & & 636.170 \\
\hline Estados Unidos....................... & & & & 972 & & & & & & & & 34.026 .191 \\
\hline Finlandia........................... & & & & & & & & & & & & 679.725 \\
\hline 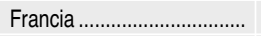 & & & & 152.000 & & & & & & 297.000 & & 520.669 .014 \\
\hline Ghana & & & & & & & & & & & & 342.735 \\
\hline 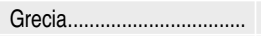 & & & & & & & & & & & 0 & 47.443 .847 \\
\hline Groenlandia (Dinamarca)... & & & & & & & & & & & & 19.786 .739 \\
\hline Guatemala............................. & & & & 680.163 & & & & & & & & 680.163 \\
\hline Hungría ................................... & & & & 5.000 & & & & & & & & 386.790 \\
\hline India .................................. & & & & & 223.887 & & & & & & 0 & 14.783 .368 \\
\hline Indonesia................................. & & & & 244.000 & & & & & & & & 112.030 .578 \\
\hline Irlanda & & & & & & & & & & & & 600.000 \\
\hline Israel ................................... & & & & 948.960 & & & & & & & & 3.428 .087 \\
\hline Italia...… & & 130.408 & & 4.413 .486 & & & & & & & & 96.126 .321 \\
\hline Jordania ................................... & & & & & & & & & & & & 190.209 \\
\hline Kazajistán............................... & & & & & & & & & & & & 53.895 .553 \\
\hline Kenia ................................ & & & & & & & & & & & & 748.250 \\
\hline Kuwait . & & & & & & & & & & & & 817.800 \\
\hline Letonia …………………........ & & & & & & & & & & & & 597.550 \\
\hline Libia................................... & & 110.041 & & & & & & & & & & 278.671 \\
\hline Luxemburgo ......................... & & & & & & & & & & & & 151.760 \\
\hline Malasia ................................... & & & & 989.800 & & & & & & & & 2.515 .279 \\
\hline 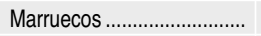 & & & & & & & & & & & & 9.702 .553 \\
\hline Mauritania .............................. & & & & & & & & & & & & 0 \\
\hline México & & & & & & & & & & & & 78.537 \\
\hline Namibia ................................ & & & & & & & & & & & & 0 \\
\hline Noruega & & & & & & & & & & & & 2.019 .626 \\
\hline Nueva Zelanda....................... & & & & & & & & & & & & 448.260 \\
\hline 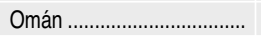 & & & & & & & & & & & & 64.893 .481 \\
\hline Países Bajos ……………....... & & & & & & & & & & & & 402.505 \\
\hline Pakistán ....……………........ & & & & 1.017 .500 & & & & & & & & 1.441 .967 \\
\hline Perú.................................. & & 578 & & & & & & & & & & 2.836 .156 \\
\hline Polonia ....……………......... & & & & & & & & & & & & 803.240 \\
\hline Portugal............................... & & & & & & & & & & & 0 & 3.472 .282 \\
\hline Reino Unido ............................ & & & & 9.080 .755 & & & & & & & 20.663 .026 & 862.685 .361 \\
\hline
\end{tabular}

Fuente: Departamento de Aduanas e IIEE (Ministerio de Hacienda y AAPP) y empresas exportadoras. Elaboración: Subdirección General de Comercio Internacional de Material de Defensa y Doble Uso. Ministerio de Economía y Competitividad. 
ESTADÍSTICAS DE LAS EXPORTACIONES ESPAÑOLAS DE MATERIAL DE DEFENSA...

3. EXPORTACIONES REALIZADAS DE MATERIAL DE DEFENSA POR PAÍSES Y ARTÍCULOS DE PRODUCTOS 2014 (continuación)

\begin{tabular}{|c|c|c|c|c|c|c|c|c|c|c|c|c|}
\hline \multirow{2}{*}{ País } & \multicolumn{11}{|c|}{ Artículos y valor en euros } & \multirow{2}{*}{$\begin{array}{l}\text { Valor } \\
\text { euros }\end{array}$} \\
\hline & 12 & 13 & 14 & 15 & 16 & 17 & 18 & 19 & 20 & 21 & 22 & \\
\hline 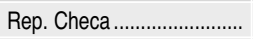 & & & & & & & & & & & & 1.863 .218 \\
\hline Rumanía............................. & & & & & & & & & & & & 150 \\
\hline 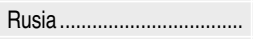 & & & & & & & & & & & & 6.865 \\
\hline Serbia ................................... & & & & & & & & & & & & 10.265 \\
\hline Seychelles............................. & & & & & & & & & & & & 11.730 \\
\hline 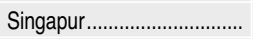 & & & & & & & & & & & & 2.330 .091 \\
\hline Suecia & & 2.468 .654 & & 4.800 & & & & & & & & 10.099 .510 \\
\hline Suiza ................................... & & & & & & & & & & 5.492 .220 & & 7.225 .188 \\
\hline 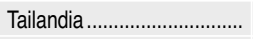 & & & & 853.572 & & & & & & & & 3.431 .528 \\
\hline Tanzania............................. & & & & & & & & & & & & 33.000 \\
\hline Túnez .................................... & & 390.000 & & & & & & & & & & 1.611 .600 \\
\hline Turquía ................................ & & & & & & & & & & & & 243.673 .494 \\
\hline Uruguay................................ & & & & 381.467 & & & & & & & & 1.101 .413 \\
\hline Venezuela ............................. & & 3.488 .628 & & & & & & & & & & 10.778 .850 \\
\hline 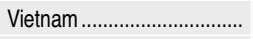 & & & & & & & & & & & & 36.491 .579 \\
\hline Zambia .................................... & & & & & & & & & & & & 8.126 \\
\hline 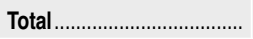 & & 6.588 .309 & 83.983 & 38.307 .133 & 283.887 & & & & & 5.789 .220 & 20.663 .026 & 3.203.248.424 \\
\hline
\end{tabular}

4. EXPORTACIONES AUTORIZADAS DE MATERIAL DE DEFENSA SUPERIORES A 100 MILLONES DE EUROS 2014

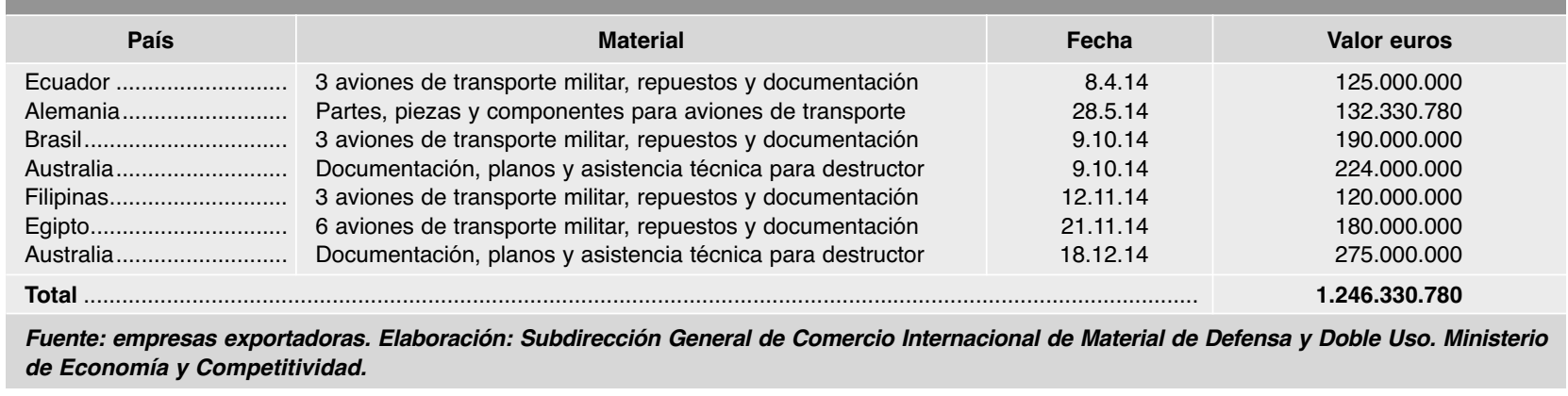

5. EXPORTACIONES REALIZADAS DE MATERIAL DE DEFENSA SUPERIORES A 10 MILLONES DE EUROS 2014

\begin{tabular}{|c|c|c|}
\hline País & Material & Valor euros \\
\hline Reino Unido ...................... & 3 aviones de reabastecimiento en vuelo y 1 avión de transporte, partes y piezas & 776.342 .007 \\
\hline Francia ............................ & 4 aviones de transporte, repuestos, equipos de tierra y documentación & 477.547 .222 \\
\hline Arabia Saudí ..................... & 1 avión de reabastecimiento en vuelo, repuestos y municiones de carro de combate & 266.020 .760 \\
\hline Alemania........................... & 1 avión de transporte, partes y piezas de aeronaves y datos técnicos & 200.255.142 \\
\hline Turquía............................ & 2 aviones de transporte, repuestos, equipos de tierra y documentación & 238.841 .651 \\
\hline Indonesia .......................... & 2 aviones de transporte, repuestos, equipos de tierra y documentación & 108.959 .575 \\
\hline Australia.......................... & Bloques para la construcción de destructores y lanchas de desembarco & 108.102 .086 \\
\hline Egipto............................. & 4 aviones de transporte, repuestos, equipos de tierra y documentación & 104.422 .262 \\
\hline Ecuador ......................... & 3 aviones de transporte, repuestos, equipos de tierra y documentación & 79.154 .877 \\
\hline Omán .............................. & 1 avión de transporte, repuestos, equipos de tierra y documentación & 55.772 .171 \\
\hline Kazajistán ......................... & 2 aviones de transporte, repuestos, equipos de tierra y documentación & 53.892 .411 \\
\hline Vietnam.......................... & 1 avión de transporte, repuestos, equipos de tierra y documentación & 36.491 .579 \\
\hline Grecia ............................... & Combustible de aviación & 28.621 .222 \\
\hline Bahrein ............................ & Munición de artillería de diversos calibres & 26.622 .200 \\
\hline Brasil............................... & 1 avión modernizado en configuración de patrulla marítima & 24.054 .972 \\
\hline Groenlandia (Dinamarca) . & Combustible de aviación & 19.786 .739 \\
\hline Camerún ........................... & 2 embarcaciones de vigilancia costera más repuestos & 11.932 .225 \\
\hline Italia .............................. & Partes y piezas de aeronaves y datos técnicos & 10.247 .455 \\
\hline \multicolumn{2}{|l|}{ Total.. } & 2.627.066.556 \\
\hline
\end{tabular}




\section{Subdirección General de Comercio Internacional de Material de Defensa y Doble Uso}

6. EXPORTACIONES REALIZADAS DE MATERIAL DE DEFENSA

(LEASING, CESIONES, DONACIONES, SEGUNDA MANO, ASISTENCIA TÉCNICA Y PRODUCCIÓN BAJO LICENCIA) 2014

País

Descripción

No hay en este periodo
Operación

Valor euros

Fuente: empresas exportadoras. Elaboración: Subdirección General de Comercio Internacional de Material de Defensa y Doble Uso. Ministerio de Economía y Competitividad.

\begin{tabular}{|c|c|c|c|c|c|c|c|c|c|}
\hline \multirow[b]{2}{*}{ País } & \multicolumn{8}{|c|}{ Programa } & \multirow{2}{*}{$\begin{array}{l}\text { Valor } \\
\text { euros }\end{array}$} \\
\hline & A400M & EF-2000 & $\begin{array}{l}\text { Misil } \\
\text { ESSM }\end{array}$ & $\begin{array}{l}\text { Misil } \\
\text { IRIS-T }\end{array}$ & $\begin{array}{c}\text { Misil } \\
\text { METEOR }\end{array}$ & MIDS & MRTT & TIGRE & \\
\hline Alemania.................. & 179.180 .466 & 76.499 .186 & & 6.412 .825 & & 74.000 & & 5.075 .732 & 267.242.209 \\
\hline Bélgica....................... & 66.500 & & & & & & & & 66.500 \\
\hline Canadá ...................... & & & 476.394 & & & & & & 476.394 \\
\hline Estados Unidos ........ & & & 2.031 .237 & & & & & & 2.031 .237 \\
\hline Francia ...................... & 488.325 .992 & & & & & 152.000 & & 3.983 .726 & 492.461 .718 \\
\hline Italia ........................ & & 31.278 .455 & & & & 1.748 .568 & & & 33.027 .023 \\
\hline Reino Unido.............. & 149.335 .447 & 84.537 .144 & & & 12.337 .496 & & 582.674 .949 & & 828.885 .036 \\
\hline Turquía ...................... & 240.063 .965 & & & & & & & & 240.063 .965 \\
\hline Total ….................. & 1.056.972.370 & 192.314 .785 & 2.507 .631 & 6.412 .825 & 12.337 .496 & 1.974 .568 & 582.674 .949 & 9.059 .458 & 1.864.254.082 \\
\hline
\end{tabular}

8. DENEGACIONES APLICADAS EN LA EXPORTACIÓN DE MATERIAL DE DEFENSA

2014

\begin{tabular}{|c|c|c|c|c|}
\hline País & Número & Material & & Criterio (Posición Común 2008/944/PESC) \\
\hline \multirow{4}{*}{ Sudán del Sur.......... } & \multirow{4}{*}{$1 \mathrm{AP}$} & \multirow{4}{*}{4 aviones de transporte militar } & 2 & $\begin{array}{l}\text { Respeto de los derechos humanos en el país de destino } \\
\text { final }\end{array}$ \\
\hline & & & 3 & $\begin{array}{l}\text { Situación interna del país de destino final, en términos de la } \\
\text { existencia de tensiones o conflictos armados }\end{array}$ \\
\hline & & & 7 & $\begin{array}{l}\text { Existencia del riesgo de que el equipo se desvíe dentro del } \\
\text { país comprador o se reexporte en condiciones no deseadas }\end{array}$ \\
\hline & & & 8 & $\begin{array}{l}\text { Compatibilidad de las exportaciones de armas con la } \\
\text { capacidad económica y técnica del país receptor, teniendo } \\
\text { en cuenta la conveniencia de que los Estados satisfagan sus } \\
\text { necesidades legítimas de seguridad y defensa con el mínimo } \\
\text { desvío de recursos humanos y económicos para } \\
\text { armamentos }\end{array}$ \\
\hline
\end{tabular}

Fuente: Subdirección General de Comercio Internacional de Material de Defensa y Doble Uso. Ministerio de Economía y Competitividad.

\begin{tabular}{|c|c|c|c|}
\hline \multicolumn{4}{|c|}{$\begin{array}{l}\text { 9. SUSPENSIONES APLICADAS EN LA EXPORTACIÓN DE MATERIAL DE DEFENSA } \\
\qquad 2014\end{array}$} \\
\hline País & Número & Material & Motivo \\
\hline Ucrania................ & 1 & Rifle & $\begin{array}{l}\text { Situación de inestabilidad interna y riesgo de } \\
\text { desvío en el uso }\end{array}$ \\
\hline Venezuela ............ & 3 & Máscaras antigás y materia prima & $\begin{array}{l}\text { Situación de inestabilidad interna y riesgo de } \\
\text { desvío en el uso }\end{array}$ \\
\hline
\end{tabular}


ESTADÍSTICAS DE LAS EXPORTACIONES ESPAÑOLAS DE MATERIAL DE DEFENSA...

10. DESCRIPCIÓN DE LOS 22 ARTíCULOS DE LA RELACIÓN DE MATERIAL DE DEFENSA

(REAL DECRETO 379/2014, DE 1 DE AGOSTO)

\begin{tabular}{|l|l|} 
Artículo & \multicolumn{1}{c}{ Descripción } \\
\hline 1 & $\begin{array}{l}\text { Armas con cañón de ánima lisa con un calibre inferior } \\
\text { a } 20 \mathrm{~mm} .\end{array}$ \\
\hline
\end{tabular}

2

Armas con cañón de ánima lisa con un calibre igual o superior a $20 \mathrm{~mm}$.

Municiones y dispositivos para el armado de los cebos

Bombas, torpedos, cohetes, misiles

Sistemas de dirección de tiro

Vehículos terrenos

Agentes químicos o biológicos tóxicos

Materiales energéticos y sustancias relacionadas

Buques de guerra

Aeronaves

Equipos electrónicos

Sistemas de armas de energía cinética

Equipos y construcciones blindadas

Equipos para el entrenamiento o simulación militar

Equipos criogénicos y superconductores

\section{Relación de productos incluidos}

Fusiles y armas combinadas, armas cortas, ametralladoras, fusiles ametralladoras, armas multitubo, armas con cañón de ánima lisa, armas que utilizan municiones sin vaina, cargadores desmontables, supresores o moderadores del ruido, montajes especiales de cañón, visores ópticos y apagafogonazos Armas de fuego (incluidas las piezas de artillería), rifles, obuses, cañones, morteros, armas contracarro, lanzaproyectiles, lanzallamas, rifles sin retroceso, dispositivos para la reducción de la firma, proyectores o generadores militares para humos, gases, material pirotécnico, visores y montajes y cargadores desmontables Municiones para las armas sometidas a control por los artículos 1, 2 ó 12. Dispositivos para el armado de los cebos, se incluyen las vainas, los eslabones, las cintas, las fuentes de alimentación de elevada potencia de salida, los sensores, las submuniciones, incluidas pequeñas bombas, minas y proyectiles con guiado final Bombas, torpedos, granadas, botes de humo, cohetes, minas, misiles, cargas de profundidad, cargas de demolición, «productos pirotécnicos», cartuchos y simuladores, granadas fumígenas, bombas incendiarias, toberas de cohetes de misiles y puntas de ojiva de vehículos de reentradas

Visores de armas, ordenadores de bombardeo, equipo de puntería para cañones, sistemas de control para armas y sistemas de adquisición de datos, de vigilancia o rastreo, reconocimiento o identificación

Vehículos terrenos diseñados especialmente o modificados para uso militar, carros y otros vehículos militares armados o equipos para el sembrado de minas, vehículos blindados, vehículos anfibios, los neumáticos a prueba de bala Agentes biológicos y materiales radiactivos, agentes nerviosos, vesicantes, gases lacrimógenos, agentes antidisturbios

Explosivos, propulsantes, productos pirotécnicos, combustibles para aeronaves, percloratos, cloratos y cromatos, oxidantes, aglomerantes, aditivos y precursores

Buques de superficie o subacuáticos, motores diésel diseñados especialmente para submarinos, motores eléctricos diseñados especialmente para submarinos, aparatos de detección subacuática, redes antisubmarinos y antitorpedos

Aeronaves de combate, vehículos aéreos no tripulados, motores aeronáuticos, vehículos aéreos teledirigidos, abastecedores de combustible, equipos de respiración presurizados, paracaídas, parapentes y sistemas de pilotaje automático

Equipos de contramedidas y contra-contramedidas electrónicas, material acústico submarino, equipos de seguridad de los datos, equipos que utilicen cifrado, equipos de guiado, navegación y transmisiones

Sistemas de armas de energía cinética, instalaciones de ensayo y de evaluación y modelos de prueba, sistemas de propulsión, sistemas de búsqueda de objetivos, de guiado o de propulsión derivada para proyectiles

Planchas de blindaje, construcciones de materiales metálicos o no, cascos militares, trajes blindados y prendas de protección

Entrenadores de ataque, de vuelo, de blancos radar, de guerra antisubmarina, para el lanzamiento de misiles, de generación de imagen

Registradores y equipos de proceso de imagen, cámaras, equipo fotográfico, equipo para la intensificación de imágenes, equipo de formación de imagen de infrarrojos o térmica, equipo sensor de imagen por radar

Piezas de forja, piezas de fundición y productos semielaborados

Aparatos autónomos de inmersión y natación subacuática, aparatos de circuito cerrado y semicerrado, robots, transbordadores

Instalaciones de ensayo ambiental, nitruradores de tipo continuo, equipos o aparatos de ensayo por centrifugación, prensas extruidoras de husillo

Sistemas láser, de haces de partículas, de radiofrecuencia, aceleradores de partículas

Equipos diseñados especialmente o configurados para ser instalados en vehículos para aplicaciones militares terrestres, marítimas, aeronáuticas o espaciales, equipos eléctricos superconductores

Equipo lógico (software) para la modelización, la simulación o la evaluación de sistemas de armas militares o de simulación de escenarios de operaciones militares, para las aplicaciones de mando, comunicaciones, control e inteligencia Tecnología para el desarrollo, producción o utilización de los materiales sometidos a control

Fuente: Subdirección General de Comercio Internacional de Material de Defensa y Doble Uso. Ministerio de Economía y Competitividad. 


\section{Subdirección General de Comercio Internacional de Material de Defensa y Doble Uso}

\begin{tabular}{|c|c|c|}
\hline \multicolumn{3}{|c|}{$\begin{array}{l}\text { 11. EXPORTACIONES AUTORIZADAS DE OTRO MATERIAL } \\
\text { (ANTIDISTURBIOS) POR PAÍS } \\
2014\end{array}$} \\
\hline País & $\mathbf{N}^{\circ}$ Licencias & Valor euros \\
\hline Bolivia ..................... & 2 & 2.813 .403 \\
\hline Libia ............................ & 1 & 6.330 .440 \\
\hline Portugal....... & 1 & 13.015 \\
\hline Togo …......................... & 2 & 465.000 \\
\hline Túnez .......................... & 1 & 53.658 \\
\hline TOTAL $\ldots \ldots \ldots \ldots \ldots \ldots$ & 7 & 9.675 .516 \\
\hline
\end{tabular}

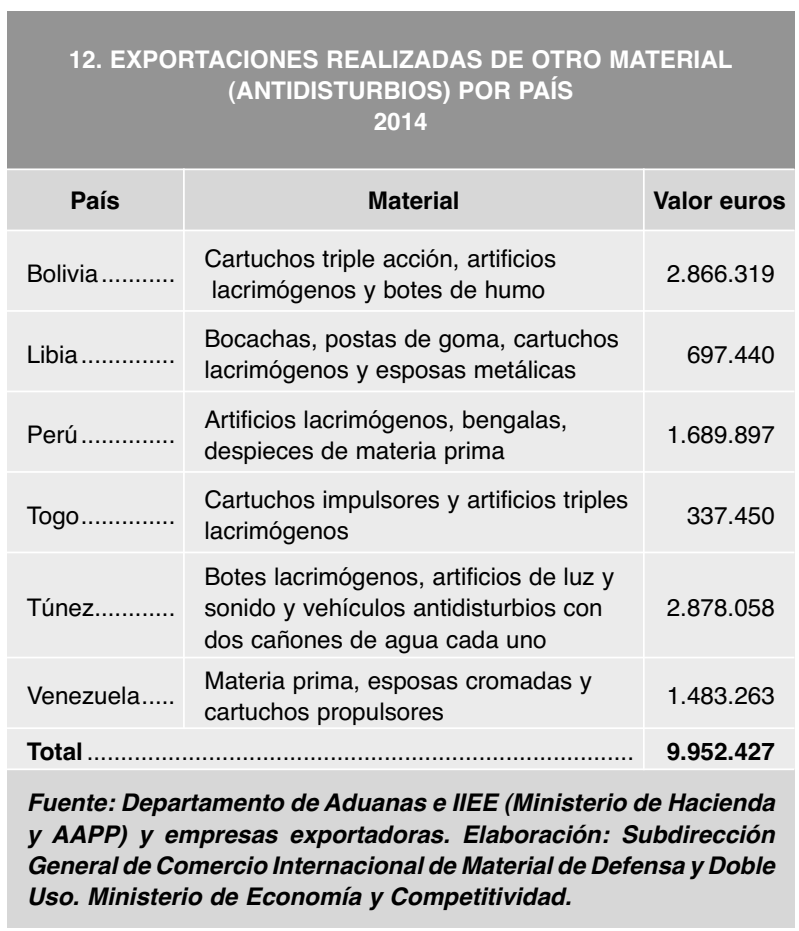

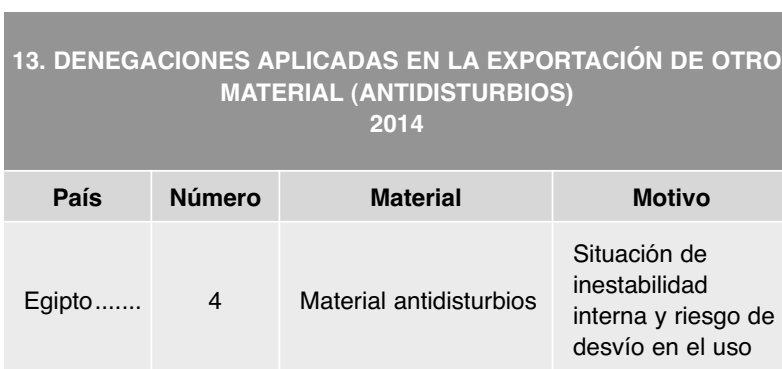

Fuente: Subdirección General de Comercio Internacional de Material de Defensa y Doble Uso. Ministerio de Economía y Competitividad.

14. EXPORTACIONES REALIZADAS DE OTRO MATERIAL (ANTIDISTURBIOS)

(LEASING, DONACIONES, SEGUNDA MANO,

ASISTENCIA TÉCNICA Y PRODUCCIÓN BAJO LICENCIA) 2014

\begin{tabular}{l|l|l|l} 
País & Material & Operación & $\begin{array}{r}\text { Valor } \\
\text { euros }\end{array}$ \\
\hline \multicolumn{2}{|c|}{ No hay en este periodo }
\end{tabular}

Fuente: empresas exportadoras. Elaboración: Subdirección General de Comercio Internacional de Material de Defensa y Doble Uso. Ministerio de Economía y Competitividad.

\begin{tabular}{|c|c|c|c|}
\hline \multicolumn{4}{|c|}{$\begin{array}{r}\text { MATERIAL (ANTID } \\
2014\end{array}$} \\
\hline País & Número & Material & Motivo \\
\hline Venezuela... & 13 & $\begin{array}{l}\text { Material antidisturbios: } \\
\text { máscaras antigás, } \\
\text { colorantes, cartuchos } \\
\text { propulsores, esposas } \\
\text { cromadas con trinquete y } \\
\text { materia prima para la } \\
\text { fabricación de artificios } \\
\text { lacrimógenos no letales }\end{array}$ & $\begin{array}{l}\text { Situación de } \\
\text { inestabilidad } \\
\text { interna y riesgo } \\
\text { de desvío en el } \\
\text { uso }\end{array}$ \\
\hline
\end{tabular}

Fuente: Subdirección General de Comercio Internacional de Material de Defensa y Doble Uso. Ministerio de Economía y Competitividad. 
ESTADÍSTICAS DE LAS EXPORTACIONES ESPAÑOLAS DE MATERIAL DE DEFENSA...

16. EXPORTACIONES AUTORIZADAS DE OTRO MATERIAL (ARMA DE CAZA Y TIRO DEPORTIVO) POR PAíS Y NÚMERO DE LICENCIAS 2014

\begin{tabular}{|c|c|c|c|c|c|}
\hline País & $\begin{array}{l}\text { Número } \\
\text { licencias }\end{array}$ & $\begin{array}{l}\text { Valor } \\
\text { euros }\end{array}$ & País & $\begin{array}{l}\text { Número } \\
\text { licencias }\end{array}$ & $\begin{array}{l}\text { Valor } \\
\text { euros }\end{array}$ \\
\hline Andorra & 11 & 349.576 & Jamaica & 2 & 148.000 \\
\hline 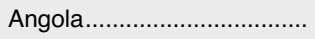 & 1 & 1.200 .000 & Japón .............. & 5 & 1.024 .078 \\
\hline Arabia Saudí .......................... & 1 & 650 & 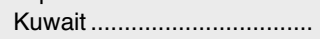 & 1 & 40.000 \\
\hline Argentina & 32 & 1.220 .080 & 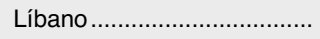 & 11 & 2.920 .930 \\
\hline Armenia .......................... & 1 & 28.000 & Marruecos ............................ & 8 & 2.136 .348 \\
\hline 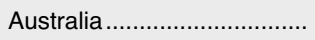 & 5 & 2.678 .350 & Mauritania ............................ & 6 & 2.980 .670 \\
\hline 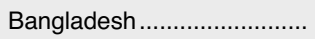 & 4 & 37.050 & 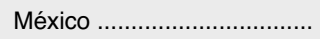 & 5 & 5.070 .000 \\
\hline 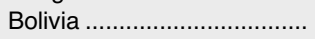 & 1 & 105.000 & 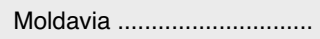 & 4 & 1.204 .000 \\
\hline 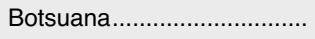 & 1 & 42.730 & 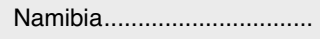 & 4 & 1.296 .358 \\
\hline 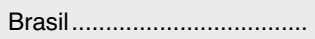 & 4 & 6.774 & 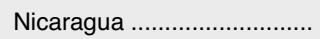 & 1 & 75.000 \\
\hline Burkina Faso.......................... & 4 & 367.569 & 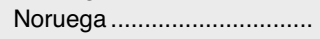 & 3 & 1.700 .000 \\
\hline 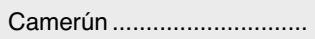 & 5 & 2.630 .800 & Nueva Cal. (Francia) ............ & 1 & 65.000 \\
\hline 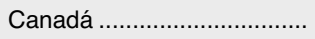 & 5 & 1.107.310 & Nueva Zelanda ...................... & 3 & 3.800 .000 \\
\hline Chile & 18 & 1.372 .670 & 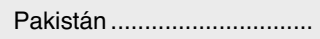 & 2 & 99.503 \\
\hline 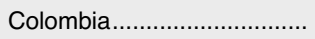 & 6 & 391.412 & Panamá & 1 & 200.000 \\
\hline Costa Rica ............................. & 1 & 72.000 & Paraguay ............................... & 3 & 915.000 \\
\hline 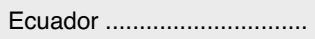 & 1 & 0 & 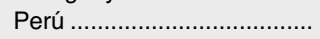 & 12 & 3.767 .250 \\
\hline 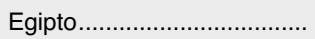 & 2 & 30 & Rep. Dominicana .................. & 2 & 360.000 \\
\hline 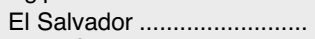 & 2 & 210.000 & 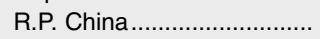 & 3 & 625.000 \\
\hline Emir. Árabes Unidos ............ & 1 & 0 & Rusia........... & 8 & 2.389 .500 \\
\hline Estados Unidos..................... & 40 & 56.055 .950 & Senegal...... & 2 & 245.000 \\
\hline 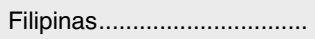 & 1 & 3.000 & Serbia .......... & 2 & 255.625 \\
\hline 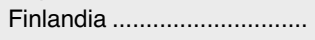 & 1 & 0 & 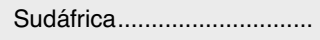 & 5 & 1.673 .400 \\
\hline 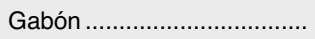 & 2 & 320.000 & Suiza & 4 & 51.000 \\
\hline Georgia & 2 & 13.000 & 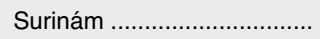 & 1 & 42.000 \\
\hline 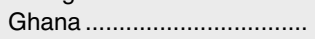 & 8 & 9.142 .000 & 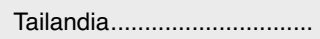 & 3 & 405.000 \\
\hline Guatemala ........................... & 4 & 331.514 & Túnez ......... & 7 & 1.378 .710 \\
\hline Guinea Ecuatorial ................ & 10 & 5.414 & 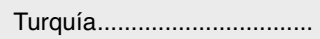 & 3 & 2.582 .500 \\
\hline 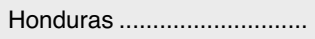 & 1 & 125.000 & Ucrania . & 8 & 2.510 .050 \\
\hline India & 2 & 72.500 & Uruguay ....... & 3 & 926.700 \\
\hline $\begin{array}{l}\text { Islandia } \\
\text { Israel }\end{array}$ & $\begin{array}{l}1 \\
4\end{array}$ & $\begin{array}{r}45.000 \\
474.746\end{array}$ & Total... & 305 & 119.294.747 \\
\hline
\end{tabular}

Fuente: Subdirección General de Comercio Internacional de Material de Defensa y Doble Uso. Ministerio de Economía y Competitividad. 


\section{Subdirección General de Comercio Internacional de Material de Defensa y Doble Uso}

\begin{tabular}{|c|c|c|}
\hline \multicolumn{3}{|c|}{$\begin{array}{l}\text { 17. EXPORTACIONES REALIZADAS DE OTRO MATERIAL (ARMA DE CAZA Y TIRO DEPORTIVO) POR PAÍS } \\
2014\end{array}$} \\
\hline País & Descripción & Valor euros \\
\hline 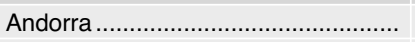 & Escopetas y cartuchos & 9.941 \\
\hline 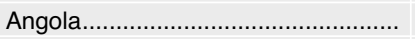 & Cartuchos & 305.000 \\
\hline 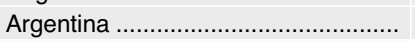 & Escopetas, vainas y partes de escopetas & 172.052 \\
\hline 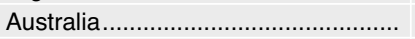 & Escopetas y cartuchos & 1.857 .391 \\
\hline 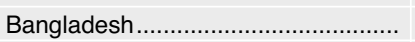 & Escopetas & 24.650 \\
\hline 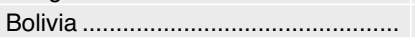 & Cartuchos y perdigones & 102.003 \\
\hline 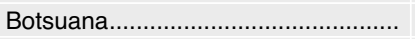 & Cartuchos & 73.811 \\
\hline Brasil....................................... & Escopetas y cartuchos & 7.565 \\
\hline Burkina Faso..................................... & Cartuchos & 180.800 \\
\hline 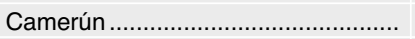 & Escopetas y cartuchos & 1.361 .438 \\
\hline 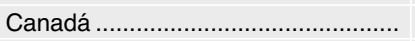 & Vainas & 187.000 \\
\hline Chile & Escopetas, cartuchos, vainas y pólvora sin humo & 1.095 .857 \\
\hline 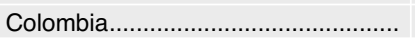 & Escopetas y vainas & 572.149 \\
\hline Costa Rica .................................... & Cartuchos & 46.655 \\
\hline Egipto......................................... & Escopetas & 20 \\
\hline Estados Unidos ............................ & Escopetas, cartuchos, partes de escopetas, vainas y pólvora sin humo & 18.933.367 \\
\hline Filipinas......................................... & Cartuchos & 28.200 \\
\hline 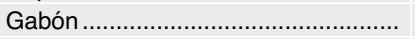 & Cartuchos & 205.103 \\
\hline 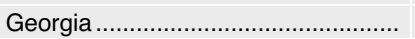 & Escopetas & 9.611 \\
\hline 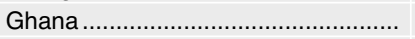 & Cartuchos & 2.251 .180 \\
\hline 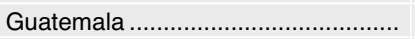 & Cartuchos & 254.077 \\
\hline Guinea Ecuatorial ........................... & Escopetas & 4.385 \\
\hline Honduras .................................... & Cartuchos & 125.000 \\
\hline India ...................................... & Pistones & 53.000 \\
\hline 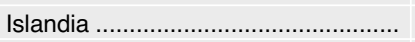 & Cartuchos & 39.950 \\
\hline Israel .............................................. & Cartuchos y pólvora sin humo & 98.127 \\
\hline Jamaica ................................... & Cartuchos & 64.250 \\
\hline Japón .............................................. & Escopetas, cartuchos, partes de escopetas, vainas y pólvora sin humo & 1.406 .556 \\
\hline Kazajistán ........................................ & Pólvora sin humo & 65.000 \\
\hline Kuwait .................................... & Cartuchos & 18.950 \\
\hline Líbano ............................................ & Escopetas, cartuchos, partes de escopetas, vainas y pólvora sin humo & 762.766 \\
\hline 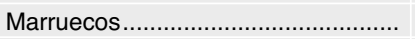 & Cartuchos y pistones & 1.315 .370 \\
\hline 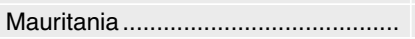 & Escopetas y cartuchos & 668.903 \\
\hline 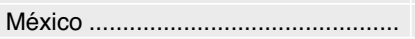 & Cartuchos y vainas & 1.218 .048 \\
\hline 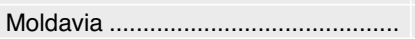 & Cartuchos & 76.210 \\
\hline 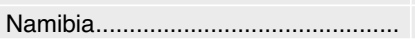 & Cartuchos & 503.648 \\
\hline 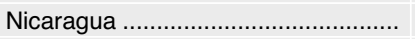 & Cartuchos & 82.051 \\
\hline 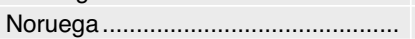 & Escopetas y cartuchos & 731.910 \\
\hline Nueva Zelanda .................................... & Escopetas y cartuchos & 337.850 \\
\hline 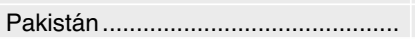 & Escopetas & 38.364 \\
\hline Panamá ….......................................... & Cartuchos & 72.690 \\
\hline 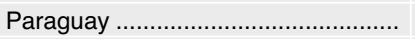 & Cartuchos & 118.000 \\
\hline 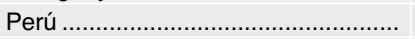 & Cartuchos & 1.391 .414 \\
\hline Rep. Dominicana .................................. & Cartuchos & 402.809 \\
\hline 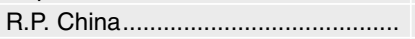 & Cartuchos & 229.390 \\
\hline 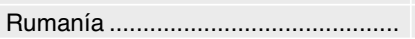 & Escopetas & 0 \\
\hline 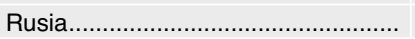 & Escopetas, cartuchos, vainas y pólvora sin humo & 1.043 .747 \\
\hline 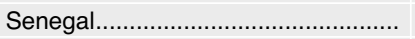 & Cartuchos & 260.980 \\
\hline Serbia & Escopetas y cartuchos & 46.010 \\
\hline Sudáfrica......................................... & Escopetas, cartuchos y perdigones & 1.797 .370 \\
\hline 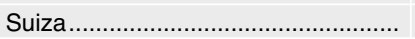 & Escopetas & 30.000 \\
\hline Surinam ….................................. & Cartuchos & 37.850 \\
\hline Tailandia.............................................. & Escopetas y cartuchos & 139.251 \\
\hline 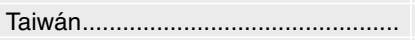 & Cartuchos & 76.690 \\
\hline Túnez ........................................ & Escopetas y cartuchos & 1.315 .686 \\
\hline 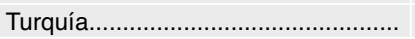 & Escopetas, cartuchos, vainas y pólvora sin humo & 2.564 .695 \\
\hline 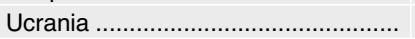 & Escopetas, cartuchos, vainas y pólvora sin humo & 1.164 .530 \\
\hline 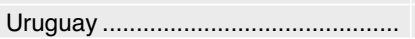 & Cartuchos & 437.614 \\
\hline Total & 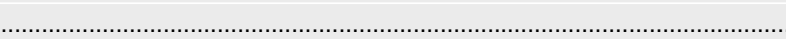 & 46.416 .934 \\
\hline
\end{tabular}


ESTADÍSTICAS DE LAS EXPORTACIONES ESPAÑOLAS DE MATERIAL DE DEFENSA...

\begin{tabular}{|c|c|c|c|}
\hline \multicolumn{4}{|c|}{$\begin{array}{l}\text { 18. EXPORTACIONES REALIZADAS DE OTRO MATERIAL (ARMA DE CAZA Y TIRO DEPORTIVO) } \\
\text { (LEASING, DONACIONES, SEGUNDA MANO, ASISTENCIA TÉCNICA Y PRODUCCIÓN BAJO LICENCIA) } \\
2014\end{array}$} \\
\hline País & Material & Operación & Valor euros \\
\hline 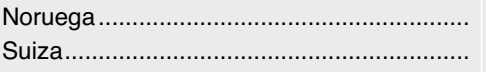 & $\begin{array}{l}1 \text { escopeta calibre } 12 \\
2 \text { escopetas calibre } 12\end{array}$ & $\begin{array}{l}\text { Donación } \\
\text { Donación }\end{array}$ & $\begin{array}{l}0 \\
0\end{array}$ \\
\hline TOTAL . & L & 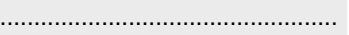 & 0 \\
\hline
\end{tabular}

\section{DENEGACIONES APLICADAS EN LA EXPORTACIÓN DE OTRO MATERIAL (ARMA DE CAZA Y TIRO DEPORTIVO)} 2014

\begin{tabular}{|c|c|c|c|c}
\hline País & Número & Material & \multicolumn{1}{c}{ Motivo } \\
\hline Guinea Bisáu & $\ldots . . . . . . . .$. & 1 & Cartuchos de caza & $\begin{array}{l}\text { Situación interna del país de destino y riesgo de desvío a otro } \\
\text { destino }\end{array}$ \\
\hline Fuente: Subdirección General de Comercio Internacional de Material de Defensa y Doble Uso. Ministerio de Economía y Competitividad.
\end{tabular}

\begin{tabular}{|c|c|c|c|}
\hline \multicolumn{4}{|c|}{$\begin{array}{l}\text { 20. SUSPENSIONES APLICADAS EN LA EXPORTACIÓN DE O' } \\
2014\end{array}$} \\
\hline País & Número & Material & Motivo \\
\hline Ucrania....................... & 11 & $\begin{array}{l}\text { Vainas con pistón, cartuchos de } \\
\text { escopeta, munición no metálica, } \\
\text { pólvora y escopetas calibre } 12\end{array}$ & Situación de inestabilidad interna y riesgo de desvío en el uso \\
\hline
\end{tabular}

21. RELACIÓN DE OTRO MATERIAL

(REAL DECRETO 679/2014, DE 1 DE AGOSTO)

Anexo II.1. armas de fuego, sus piezas y componentes esenciales y municiones para uso civil

1. Aquellas armas de fuego, así como sus partes y componentes esenciales y municiones, definidas en el anexo I del Reglamento (UE) N ${ }^{\circ} 258 / 2012$ del Parlamento Europeo y del Consejo, de 14 de marzo de 2012, por el que se aplica el artículo 10 del Protocolo de las Naciones Unidas contra la fabricación y el tráfico ilícitos de armas de fuego, sus piezas y componentes y municiones, que complementa la Convención de las Naciones Unidas contra la delincuencia transnacional organizada, y por el que se establecen autorizaciones de exportación y medidas de importación y tránsito para las armas de fuego, sus piezas y componentes y municiones

2. Visores y miras, telescópicos o de intensificación de luz o imagen, para armas de fuego, distintas de las incluidas en el anexo I.1 de este Real Decreto

Anexo II.2. relacion de otro material

1. Artificios generadores, proyectores, emisores o dispensadores de humos, gases, «agentes antidisturbios» o sustancias incapacitantes

2. Lanzadores de los elementos descritos en el apartado 1 anterior

3. Equipos de luz y sonido provocadores de aturdimiento, para el control de disturbios

4. Vehículos para el control de disturbios con alguna de las siguientes características

1. Sistemas para producir descargas eléctricas

2. Sistemas para dispensar sustancias incapacitantes

3. Sistemas para dispensar agentes antidisturbios

4. Cañones de agua

5. Esposas normales

Fuente: Subdirección General de Comercio Internacional de Material de Defensa y Doble Uso. Ministerio de Economía y Competitividad. 


\section{Subdirección General de Comercio Internacional de Material de Defensa y Doble Uso}

\begin{tabular}{|c|c|c|c|c|c|}
\hline \multicolumn{6}{|c|}{$\begin{array}{l}\text { 22. EXPORTACIONES AUTORIZADAS DE PRODUCTOS Y TECNOLOGÍAS D } \\
\text { NÚMERO DE LICENCIAS Y VALOR EN EUROS } \\
2014\end{array}$} \\
\hline País & $\begin{array}{l}\text { Número } \\
\text { licencias }\end{array}$ & $\begin{array}{l}\text { Valor } \\
\text { euros }\end{array}$ & País & $\begin{array}{l}\text { Número } \\
\text { Licencias }\end{array}$ & $\begin{array}{l}\text { Valor } \\
\text { euros }\end{array}$ \\
\hline Albania .................................. & 1 & 60.000 & Libia................................... & 5 & 5.989 \\
\hline Alemania ............................... & 1 & 0 & Malasia .................................... & 4 & 5.415 .979 \\
\hline Andorra .................................. & 4 & 233.998 & Marruecos ............................... & 13 & 1.168 .171 \\
\hline Arabia Saudí ........................... & 16 & 24.363 .016 & 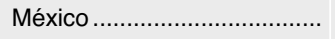 & 13 & 9.521 .282 \\
\hline Argelia................................. & 18 & 1.478 .879 & Myanmar .................................. & 1 & 1.300 .000 \\
\hline Argentina ............................ & 9 & 936.881 & Nicaragua .................................. & 2 & 146 \\
\hline 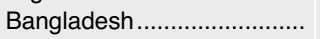 & 2 & 1.003 .334 & Nigeria ................................. & 5 & 1.176 .020 \\
\hline Brasil ...................................... & 18 & 8.465 .146 & Omán....................................... & 3 & 2.595 \\
\hline Camerún ............................... & 1 & 13.680 & Pakistán.............. & 1 & 931 \\
\hline Canadá .................................. & 3 & 12.072 .985 & Paraguay .................................. & 7 & 656.866 \\
\hline Catar .................................. & 1 & 375.000 & Perú .......................................... & 6 & 72.155 \\
\hline Chile ................................... & 5 & 132.500 & Reino Unido............................. & 2 & 151.534 \\
\hline Colombia................................ & 24 & 923.983 & Rep. Dominicana ...................... & 1 & 26 \\
\hline Corea del Sur ......................... & 14 & 660.786 & 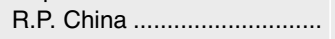 & 72 & 24.794 .383 \\
\hline Cuba & 18 & 3.051 .592 & 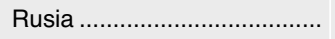 & 32 & 23.684 .221 \\
\hline Egipto ..................................... & 8 & 931.244 & 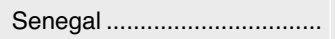 & 1 & 22.054 \\
\hline Emir. Árabes Unidos ............. & 8 & 9.287 .934 & Serbia ..................... & 2 & 8.100 \\
\hline Estados Unidos.................... & 6 & 18.602 .578 & Singapur .................................. & 2 & 2.750 \\
\hline Francia ................................ & 1 & 0 & 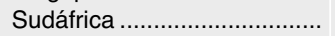 & 7 & 2.907 .060 \\
\hline Georgia ............................. & 2 & 373.300 & Tailandia .................................. & 7 & 3.810 .554 \\
\hline Guatemala ............................ & 1 & 5.000 & 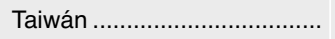 & 26 & 1.263 .067 \\
\hline Hong Kong (R.P. China) ..... & 11 & 60.000 & Túnez ..................................... & 3 & 200.023 \\
\hline 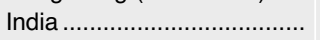 & 10 & 5.165 .961 & Turkmenistán.......................... & 1 & 188.584 \\
\hline Indonesia ................................ & 1 & 110.790 & 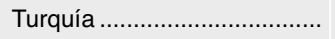 & 5 & 5.579 .297 \\
\hline Irak & 3 & 99.000 & 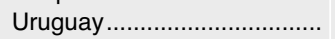 & 2 & 67.500 \\
\hline 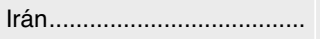 & 23 & 33.709 .588 & Venezuela............. & 3 & 4.003 .713 \\
\hline Israel ............................... & 18 & 1.122 .813 & 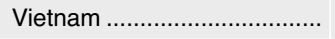 & 5 & 134.692 \\
\hline Kazajistán ............................. & 1 & 31.899 & & & \\
\hline Kuwait ................................ & 2 & 96.999 & Total ... & 461 & 209.506.578 \\
\hline
\end{tabular}


ESTADÍSTICAS DE LAS EXPORTACIONES ESPAÑOLAS DE MATERIAL DE DEFENSA...

\begin{tabular}{|c|c|c|c|c|c|c|c|c|c|c|c|}
\hline \multicolumn{12}{|c|}{$\begin{array}{l}\text { 23. EXPORTACIONES AUTORIZADAS DE PRODUCTOS Y TECN } \\
2014\end{array}$} \\
\hline \multirow{2}{*}{ País } & \multicolumn{10}{|c|}{ Categoría } & \multirow{2}{*}{$\begin{array}{l}\text { Valor } \\
\text { euros }\end{array}$} \\
\hline & 0 & 1 & 2 & 3 & 4 & 5 & 6 & 7 & 8 & 9 & \\
\hline Albania & & 60.000 & & & & & & & & & 60.000 \\
\hline Alemania & & & & 0 & & & & & & & 0 \\
\hline Andorra & & & & & & 233.998 & & & & & 233.998 \\
\hline Arabia Saudí ......................... & 229 & 5.374 .422 & 17.188 .365 & & & 1.800 .000 & & & & & 24.363 .016 \\
\hline Argelia & & 1.478 .879 & & & & & & & & & 1.478 .879 \\
\hline Argentina & & & 4.776 & 932.105 & & & & & & & 936.881 \\
\hline 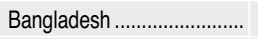 & & & 1.003 .334 & & & & & & & & 1.003 .334 \\
\hline 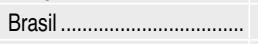 & & 3.618 .200 & 4.591 .100 & 255.846 & & 0 & & & & & 8.465 .146 \\
\hline 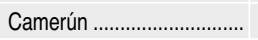 & & 13.680 & & & & & & & & & 13.680 \\
\hline 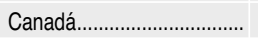 & 12.072 .985 & & & & & & & & & & 12.072 .985 \\
\hline 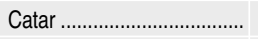 & & 375.000 & & & & & & & & & 375.000 \\
\hline 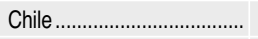 & & 132.500 & & & & & & & & & 132.500 \\
\hline 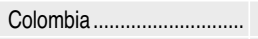 & & 840.983 & & & & & 83.000 & & & & 923.983 \\
\hline 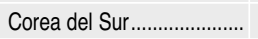 & & & 0 & 660.786 & & & & & & & 660.786 \\
\hline 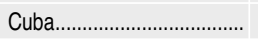 & 2.905 .000 & 138.294 & 8.298 & & & & & & & & 3.051 .592 \\
\hline Egipto & & 390.000 & 541.244 & & & & 0 & & & 0 & 931.244 \\
\hline Emir. Árabes Unidos ........... & & 186 & 9.167 .849 & 119.899 & & & & & & & 9.287 .934 \\
\hline 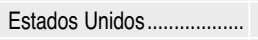 & 17.838 .138 & & & & & & & & & 764.440 & 18.602 .578 \\
\hline Francia & & 0 & & & & & & & & & 0 \\
\hline Georgia & & & & & & & & & & 373.300 & 373.300 \\
\hline Guatemala & & 5.000 & & & & & & & & & 5.000 \\
\hline Hong Kong (R.P. China)..... & & & & & & 0 & & & & 60.000 & 60.000 \\
\hline India & & 557.640 & 4.608 .321 & & & & & & & & 5.165 .961 \\
\hline 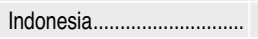 & & & & & & & 110.790 & & & & 110.790 \\
\hline Irak & & 99.000 & & & & & 0 & & & & 99.000 \\
\hline 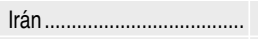 & & & 33.709 .588 & & & & & & & & 33.709 .588 \\
\hline 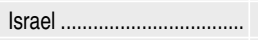 & & 470.080 & & 52.926 & & 254.807 & 0 & 255.000 & & 90.000 & 1.122 .813 \\
\hline Kazajistán............................... & & & 31.899 & & & & & & & & 31.899 \\
\hline 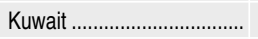 & & & 96.999 & & & & & & & & 96.999 \\
\hline 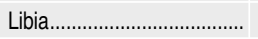 & 5.658 & 331 & & & & & & & & & 5.989 \\
\hline 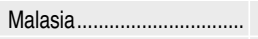 & & 1.615 .203 & & & & 3.800 .776 & & & & & 5.415 .979 \\
\hline 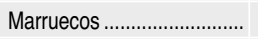 & 14.580 & 1.153 .591 & & & & & 0 & & & & 1.168 .171 \\
\hline México & 19.045 & & 7.239 .362 & & & 2.225 .891 & 36.984 & & & & 9.521 .282 \\
\hline 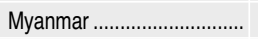 & & 1.300 .000 & & & & & & & & & 1.300 .000 \\
\hline 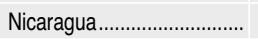 & & 146 & & & & & & & & & 146 \\
\hline 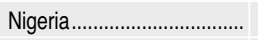 & & 1.176 .020 & & & & & & & & & 1.176 .020 \\
\hline Omán & & 2.595 & & & & & & & & & 2.595 \\
\hline 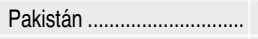 & & & 931 & & & & & & & & 931 \\
\hline 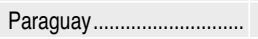 & & 653.500 & 3.366 & & & & & & & & 656.866 \\
\hline Perú.................................... & & 45.000 & & & & 7.155 & & & & 20.000 & 72.155 \\
\hline 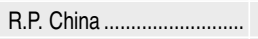 & & 1.472 .804 & 10.593 .832 & 12.632 .336 & & & 2.800 & & & 92.611 & 24.794 .383 \\
\hline 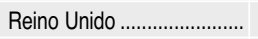 & & & & & & 151.534 & & & & & 151.534 \\
\hline Rep. Dominicana................. & & 26 & & & & & & & & & 26 \\
\hline Rusia & & 150.339 & 21.724 .815 & 1.809 .067 & & & 0 & 0 & & & 23.684 .221 \\
\hline 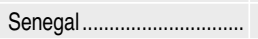 & & & & & & & 22.054 & & & & 22.054 \\
\hline Serbia & & 8.100 & & & & & & & & & 8.100 \\
\hline 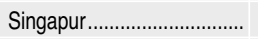 & & & & & & & 2.750 & & & & 2.750 \\
\hline 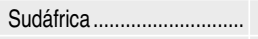 & & 1.207 .060 & & & & & 1.700 .000 & & & & 2.907 .060 \\
\hline 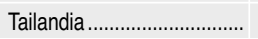 & & 10.554 & & & & 3.800 .000 & & & & & 3.810 .554 \\
\hline Taiwán & & 6.364 & 0 & 427.485 & & & 6.298 & & 822.920 & & 1.263 .067 \\
\hline 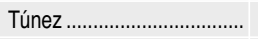 & & 200.023 & & & & & 0 & & & & 200.023 \\
\hline Turkmenistán.......................... & & & 188.584 & & & & & & & & 188.584 \\
\hline Turquía & & 485.000 & 25.866 & & & 5.068 .431 & 0 & & & & 5.579 .297 \\
\hline 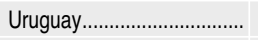 & & 67.500 & 0 & & & & & & & & 67.500 \\
\hline 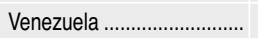 & & & 2.760 & & & 4.000 .953 & & & & & 4.003 .713 \\
\hline Vietnam & & 516 & 134.176 & & & & 0 & & & & 134.692 \\
\hline 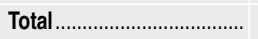 & 32.855 .635 & 23.108 .536 & 110.865 .465 & 16.890 .450 & & 21.343 .545 & 1.964 .676 & 255.000 & 822.920 & 1.400 .351 & 209.506.578 \\
\hline
\end{tabular}




\section{Subdirección General de Comercio Internacional de Material de Defensa y Doble Uso}

\begin{tabular}{|c|c|c|c|c|c|c|c|c|c|c|c|}
\hline \multirow{2}{*}{ País } & \multicolumn{10}{|c|}{ Categoría } & \multirow{2}{*}{$\begin{array}{l}\text { Valor } \\
\text { euros }\end{array}$} \\
\hline & 0 & 1 & 2 & 3 & 4 & 5 & 6 & 7 & 8 & 9 & \\
\hline 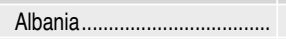 & & 26.048 & & & & & & & & & 26.048 \\
\hline 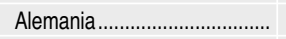 & & & & & & 3.451 & & & & & 3.451 \\
\hline 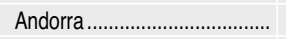 & & & & & & 467.908 & & & & & 467.908 \\
\hline Arabia Saudí .......................... & 229 & 850.733 & 882.034 & & & 273.682 & & & & & 2.006 .678 \\
\hline Argelia.......................................... & & 152.110 & & & & & & & & & 152.110 \\
\hline 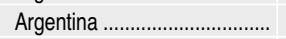 & & 704.973 & 4.776 & 497.748 & & & & & & & 1.207 .497 \\
\hline 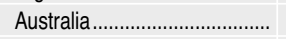 & & 7.494 & & & & & 2.750 & & & & 10.244 \\
\hline 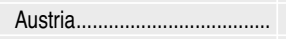 & & & & & & 308 & & & & & 308 \\
\hline 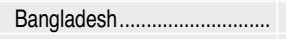 & 3.608 & & 3.196 & & & & & & & & 6.804 \\
\hline 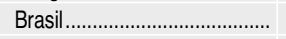 & 1.394 .714 & 279.406 & 2.895 .800 & 440.229 & & & & & & & 5.010 .149 \\
\hline Camerún ....................................... & & 13.929 & & & & & & & & & 13.929 \\
\hline 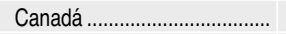 & 10.140 .755 & & & & & & 5.466 & & & & 10.146 .221 \\
\hline 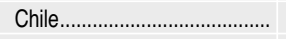 & & 315.321 & & & & & & & & & 315.321 \\
\hline 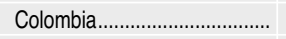 & & 430.766 & & & & & 83.000 & & & & 513.766 \\
\hline 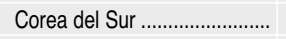 & & & 10 & 749.043 & & 8.712 & & & & & 757.765 \\
\hline Cuba & 1.636 .379 & 170.964 & 13.088 & & & & & & & & 1.820 .431 \\
\hline 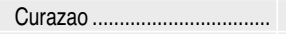 & & 533.478 & & & & & & & & & 533.478 \\
\hline 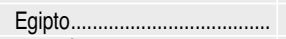 & & 190.680 & 552 & & & & & & & & 191.232 \\
\hline Emir. Árabes. Unidos.............. & & 209 & 6.854 .381 & & & & & & & & 6.854 .590 \\
\hline Estados Unidos......................... & 12.873 .020 & 200.132 & 17.163 .569 & 275 & & 358.209 & 14.358 & & & 228.736 & 30.838 .299 \\
\hline 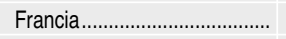 & & 0 & & & & & & & & & 0 \\
\hline 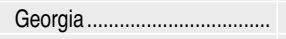 & & & & & & & & & & 231.200 & 231.200 \\
\hline Guatemala & & 3.400 & & & & & & & & & 3.400 \\
\hline Hong Kong (R.P. China) ........ & & & & 214.063 & 1.296 .000 & & & & & & 1.510 .063 \\
\hline 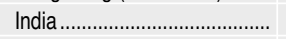 & & 17.448 & 747.822 & 212.623 & & 512 & & & & & 978.405 \\
\hline Indonesia .................................. & & & & & & & 110.318 & & & & 110.318 \\
\hline 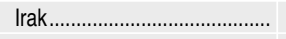 & & 99.000 & & & & & & & & & 99.000 \\
\hline |rán & & & 26.446 .008 & & & & & & & & 26.446 .008 \\
\hline 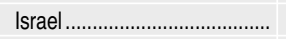 & & 66.580 & 2.277 .000 & 52.926 & & 256.230 & & & & 270.000 & 2.922 .736 \\
\hline 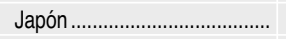 & & 200.000 & 5.205 .070 & 1.227 & 549.835 & 323 & 16.808 & & & & 5.973 .263 \\
\hline 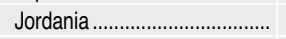 & & 4.804 & & & & & & & & & 4.804 \\
\hline Kazajistán .................................... & & & 31.899 & & & & & & & 22 & 31.921 \\
\hline 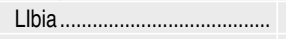 & 5.658 & 331 & & & & & & & & & 5.989 \\
\hline Malasia & & & & & & 7.741 & & & & & 7.741 \\
\hline Marruecos................................. & 2.611 & 603.938 & & & & & & & & & 606.549 \\
\hline 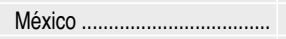 & 4.971 & & 5.460 .429 & & & 2.277 .792 & 55.646 & & & & 7.798 .838 \\
\hline 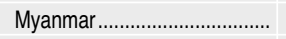 & & 1.211 .000 & & & & & & & & & 1.211 .000 \\
\hline Nicaragua .................................... & & 146 & & & & & & & & & 146 \\
\hline 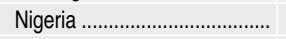 & & 234.745 & & & & & & & & & 234.745 \\
\hline 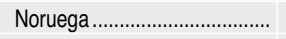 & & 859.682 & 839.170 & 22.451 & & & & & & & 1.721 .303 \\
\hline Nueva Zelanda .......................... & & 202 & & & & & & & & & 202 \\
\hline Omán & & 1.980 & & & & & & & & & 1.980 \\
\hline 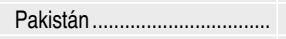 & & & 756 & & & & & & & & 756 \\
\hline 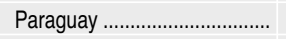 & & 372.924 & 6.732 & & & & & & & & 379.656 \\
\hline Perú ............................................. & & 5.370 & & & & & & & & & 5.370 \\
\hline Rep. Dominicana ..................... & & 26 & & & & & & & & & 26 \\
\hline R.P. China & & & 17.769 .628 & 5.499 .574 & & 3.267 & 2.800 & & & 55.239 & 23.330 .508 \\
\hline 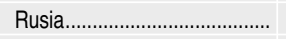 & & 157.739 & 13.380 .621 & 863.751 & & & & & & 0 & 14.402 .111 \\
\hline Serbia & & 1.540 & & & & & & & & & 1.540 \\
\hline 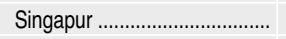 & & 0 & & 2.151 & & 4.183 & 4.250 & & & & 10.584 \\
\hline 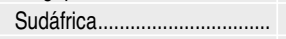 & & 560.304 & 3.142 & & & & & & & & 563.446 \\
\hline 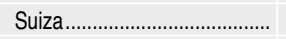 & & 45.306 & & & & 10 & & & & & 45.316 \\
\hline Tailandia................................... & & 8.390 & & & & 592.800 & & & & & 601.190 \\
\hline 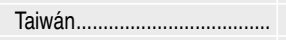 & & 4.694 & 30 & & & 2.408 & 6.298 & & 284.800 & & 298.230 \\
\hline Túnez................................. & & & 819.680 & & & & & & & & 819.680 \\
\hline Turkmenistán ............................ & & & 188.584 & & & & & & & & 188.584 \\
\hline Turquía.................................. & & 648.579 & 29.033 & & & 6.816 .488 & & & & & 7.494 .100 \\
\hline Ucrania .................................... & & 3.925 & & & & & & & & & 3.925 \\
\hline Uruguay .................................. & & 166.557 & 0 & & & & & & & & 166.557 \\
\hline Venezuela .............................. & & 5.255 .666 & & & & 4.015 .117 & & & & & 9.270 .783 \\
\hline 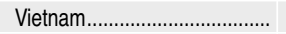 & & 688 & 134.176 & & & & & & & & 134.864 \\
\hline Yemen & & 250 & & & & & & & & & 250 \\
\hline Total. & 26.061 .945 & 14.411 .457 & 101.157.186 & 8.556 .061 & 1.845 .835 & 15.089 .141 & 301.694 & & 284.800 & 785.197 & 168.493 .316 \\
\hline
\end{tabular}


ESTADÍSTICAS DE LAS EXPORTACIONES ESPAÑOLAS DE MATERIAL DE DEFENSA...

25. DENEGACIONES APLICADAS EN LA EXPORTACIÓN DE PRODUCTOS Y TECNOLOGÍAS DE DOBLE USO 2014

\begin{tabular}{|c|c|c|c|}
\hline País & Número & Producto & Motivo \\
\hline India & 1 & Un centro de mecanizado & Riesgo de desvío a programas de proliferación nuclear y de misiles \\
\hline Irán & 1 & Una válvula en acero al carbono & Usuario final sancionado (Anexo IX del Reglamento 267/2012) \\
\hline Rusia.............................. & 1 & Una máquina de electroerosión & Riesgo de desvío a programas de proliferación nuclear y de misiles \\
\hline
\end{tabular}

26. APLICACIÓN DE LA CLÁUSULA CATCH-ALL EN LA EXPORTACIÓN DE PRODUCTOS Y TECNOLOGÍAS DE DOBLE USO 2014

\begin{tabular}{|c|c|c|c|}
\hline País & Número & Producto & Motivo \\
\hline Bielorrusia .................................... & 1 & Una máquina de electroerosión & $\begin{array}{l}\text { Riesgo de desvío a programas de proliferación nuclear y de } \\
\text { misiles }\end{array}$ \\
\hline Irán............. & 2 & Válvulas en acero inoxidable & $\begin{array}{l}\text { Riesgo de desvío a programas de proliferación nuclear y de } \\
\text { misiles }\end{array}$ \\
\hline Rusia............ & 1 & Centro de fresado & $\begin{array}{l}\text { Riesgo de desvío a programas de proliferación nuclear y de } \\
\text { misiles }\end{array}$ \\
\hline 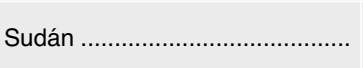 & 1 & Repuestos para máquinas-herramienta & $\begin{array}{l}\text { Riesgo de desvío a programas de proliferación nuclear y de } \\
\text { misiles }\end{array}$ \\
\hline
\end{tabular}

Fuente: Subdirección General de Comercio Internacional de Material de Defensa y Doble Uso. Ministerio de Economía y Competitividad.

\begin{tabular}{|c|c|c|}
\hline \multicolumn{3}{|c|}{$\begin{array}{l}\text { 27. EXPORTACIONES REALIZADAS DE PRODUCTOS Y TECNOLOGIAS DE DOBLE USO } \\
\text { SUPERIORES A } 10 \text { MILLONES DE EUROS } \\
2014\end{array}$} \\
\hline País & Descripción & Valor euros \\
\hline Estados Unidos .................... & Máquinas encintadoras y cabezal encintado & 11.761 .607 \\
\hline Irán & Conjuntos para hornos industriales de reducción directa & 10.600 .000 \\
\hline 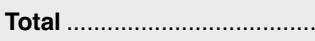 & (2) & 22.361.607 \\
\hline
\end{tabular}




\section{Subdirección General de Comercio Internacional de Material de Defensa y Doble Uso}

\begin{tabular}{|c|c|c|c|c|c|}
\hline \multicolumn{6}{|c|}{$\begin{array}{l}\text { 28. DESCRIPCIÓN DE LAS } 10 \text { CATEGORÍAS DE PRODUCTOS Y TECNOLOGÍAS DE DOBLE USO } \\
\text { (REGLAMENTO CE 428/2009, DE } 5 \text { DE MAYO) }\end{array}$} \\
\hline Categoría & \multicolumn{3}{|c|}{ Descripción 10 categorías } & \multicolumn{2}{|c|}{ Relación de productos incluidos } \\
\hline 0 & \multicolumn{3}{|c|}{ Materiales, instalaciones y equipos nucleares } & \multicolumn{2}{|c|}{$\begin{array}{l}\text { Reactores nucleares, plantas para la separación de isótopos de ura- } \\
\text { nio natural, uranio empobrecido y materiales fisionables, centrifuga- } \\
\text { doras de gas, espectrómetros de masas y electrodos de grafito }\end{array}$} \\
\hline 1 & \multicolumn{3}{|c|}{$\begin{array}{l}\text { Materiales, sustancias químicas «microorganismos»y } \\
\text { «toxinas» }\end{array}$} & \multicolumn{2}{|c|}{$\begin{array}{l}\text { Equipos de protección y detección: trajes, guantes y calzado, vehícu- } \\
\text { los de control remoto, dosímetros personales, preimpregnados, herra- } \\
\text { mientas, troqueles, moldes, mezcladoras continuas, máquinas para el } \\
\text { devanado de filamentos, fluidos y sustancias lubricantes, fluoruros, sul- } \\
\text { furos, cianuros y derivados halogenados }\end{array}$} \\
\hline 2 & \multicolumn{3}{|c|}{ Tratamiento de los materiales } & \multicolumn{2}{|c|}{$\begin{array}{l}\text { Rodamientos, crisoles, máquinas-herramienta, prensas isostáticas, ins- } \\
\text { trumentos de medida, robots, simuladores de movimientos y centros de } \\
\text { mecanizado }\end{array}$} \\
\hline 3 & \multicolumn{3}{|c|}{ Electrónica } & \multicolumn{2}{|c|}{$\begin{array}{l}\text { Componentes electrónicos, circuitos integrados, microcircuitos de mi- } \\
\text { croprocesador, conjuntos de puertas programables, componentes de } \\
\text { microondas, mezcladores y convertidores y detonadores explosivos ac- } \\
\text { cionados eléctricamente }\end{array}$} \\
\hline 4 & \multicolumn{3}{|c|}{ Ordenadores } & \multicolumn{2}{|c|}{$\begin{array}{l}\text { Ordenadores electrónicos, híbridos, digitales, analógicos, de conjunto } \\
\text { sistólico, neuronales y ópticos }\end{array}$} \\
\hline 5 & \multicolumn{3}{|c|}{ Telecomunicaciones y «seguridad de la información» } & \multicolumn{2}{|c|}{$\begin{array}{l}\text { Equipos y sistemas de transmisión para telecomunicaciones, sistemas } \\
\text { de comunicaciones subacuáticos, equipos de radio, cables de fibra óp- } \\
\text { tica, equipos de telemedida y telecontrol y sistemas de seguridad }\end{array}$} \\
\hline 6 & \multicolumn{3}{|c|}{ Sensores y láseres } & \multicolumn{2}{|c|}{$\begin{array}{l}\text { Acústica, tubos intensificadores de imagen, sensores ópticos, cámaras } \\
\text { de instrumentos, óptica, láseres, gravímetros y gradiómetros de gra- } \\
\text { vedad y sistemas de radar }\end{array}$} \\
\hline 7 & \multicolumn{3}{|c|}{ Navegación y aviónica } & \multicolumn{2}{|c|}{$\begin{array}{l}\text { Acelerómetros para navegación inercial, giroscopios, GPS y GLONASS, } \\
\text { sistemas de control de vuelo hidráulicos, mecánicos, electroópticos y } \\
\text { electromecánicos incluidos los de control por señales eléctricas (fly by } \\
\text { wire) }\end{array}$} \\
\hline 8 & \multicolumn{3}{|c|}{ Marina } & \multicolumn{2}{|c|}{$\begin{array}{l}\text { Vehículos sumergibles o buques de superficie, hidroplanos, sistemas } \\
\text { de visión subacuática, aparatos de buceo y natación subacuática }\end{array}$} \\
\hline 9 & \multicolumn{3}{|c|}{$\begin{array}{l}\text { Sistemas de propulsión, vehículos espaciales } \\
\text { y equipos relacionados }\end{array}$} & \multicolumn{2}{|c|}{$\begin{array}{l}\text { Motores aeronáuticos o marinos de turbina de gas, lanzaderas espa- } \\
\text { ciales y vehículos espaciales, sistemas de propulsión de cohetes de } \\
\text { propulsante sólido o líquido, motores estatorreactores, turborreactores } \\
\text { y turbofanes, cohetes de sondeo, motores híbridos para cohetes, equi- } \\
\text { pos de apoyo al lanzamiento, cámaras ambientales y anecoicas y ve- } \\
\text { hículos de reentrada }\end{array}$} \\
\hline \multirow{2}{*}{\multicolumn{6}{|c|}{$\begin{array}{l}\text { Fuente: Subdirección General de Comercio Internacional de Material de Defensa y Doble Uso. Ministerio de Economía y Competitivic } \\
\begin{array}{c}\text { 29. EXPORTACIONES AUTORIZADAS Y REALIZADAS DE MATERIAL DE DEFENSA, DE OTRO MATERIAL Y DE PRODUCTOS } \\
\text { Y TECNOLOGIAS DE DOBLE USO } \\
2014\end{array}\end{array}$}} \\
\hline & & & & & \\
\hline & \multirow{2}{*}{\multicolumn{2}{|c|}{$\begin{array}{l}\text { Material de defensa } \\
\text { (Valor euros) }\end{array}$}} & \multicolumn{2}{|r|}{$\begin{array}{l}\text { Otro material } \\
\text { (Valor euros) }\end{array}$} & \multirow{2}{*}{$\begin{array}{l}\text { Doble uso } \\
\text { (Valor euros) }\end{array}$} \\
\hline & & & Antidisturbios & Arma de caza y tiro deportivo & \\
\hline $\begin{array}{l}\text { Autorizado .......... } \\
\text { Realizado.......... } \\
\text { Porcentaje ........ }\end{array}$ & …..... & $\begin{array}{c}3.666 .401 .762 \\
3.203 .248 .424 \\
87,4\end{array}$ & $\begin{array}{l}9.675 .516 \\
9.952 .427 \\
102,9\end{array}$ & $\begin{array}{c}119.294 .747 \\
46.416 .934 \\
38,9\end{array}$ & $\begin{array}{l}209.506 .578 \\
168.493 .316 \\
80,4\end{array}$ \\
\hline
\end{tabular}

